\title{
Frugivoria de Ficus (Moraceae) por aves em paisagens com diferentes níveis de fragmentação florestal no
}

\section{Estado de São Paulo}

\author{
Mariana Esther Lapate
}

Dissertação apresentada à Faculdade de Filosofia, Ciências e Letras de Ribeirão Preto da USP, como parte das exigências para a obtenção do título de Mestre em Ciências, Área: Biologia Comparada

RIBEIRÃO PRETO -SP 


\title{
Frugivoria de Ficus (Moraceae) por aves em paisagens com diferentes níveis de fragmentação florestal no
}

\section{Estado de São Paulo}

\author{
Mariana Esther Lapate
}

Dissertação apresentada à Faculdade de Filosofia, Ciências e Letras de Ribeirão Preto da USP, como parte das exigências para a obtenção do título de Mestre em Ciências, Área: Biologia Comparada

Orientador: Rodrigo Augusto Santinelo Pereira

RIBEIRÃO PRETO -SP 


\section{FICHA CATALOGRÁFICA}

Lapate, Mariana Esther

Frugivoria de Ficus (Moraceae) por aves em paisagens com diferentes níveis de fragmentação florestal no Estado de São Paulo. Ribeirão Preto, 2009.

51 p. : il. ; $30 \mathrm{~cm}$

Dissertação de Mestrado, apresentada à Faculdade de Filosofia, Ciências e Letras de Ribeirão Preto/USP. Área de concentração: Biologia Comparada.

Orientador: Pereira, Rodrigo Augusto Santinelo.

1. Interação animal-planta. 2. Espécie-chave. 3. Dispersão de sementes. 4. Fragmentos florestais. 5. Floresta Estacional Semidecidual. 


\section{Agradecimentos}

Ao Programa de Pós-graduação em Biologia Comparada pela oportunidade de realização deste trabalho.

Ao Instituto Florestal do Estado de São Paulo pela autorização e apoio logístico no trabalho de campo.

À CAPES pela concessão da bolsa de estudo, à PROAP-CAPES e à FAPESP (04/10299-4) pelo auxílio financeiro.

Ao Prof. Rodrigo Augusto Santinelo Pereira, pela oportunidade, orientação, confiança, incentivo, entusiasmo e amizade ao longo desses anos.

Ao Prof. Luis Fábio da Silveira por autorizar e supervisionar a visita à coleção de aves do Museu de Zoologia da USP.

Aos professores Flávio A. Bockmann, Tiana Kohlsdorf, Reginaldo Donatelli John C. McNamara, Luiz Octavio M. Machado pelas sugestões na elaboração e realização do projeto.

Aos demais docentes do Programa de Biologia Comparada por mostrarem, cada um à sua maneira, novos caminhos para compreender melhor a Biologia.

Aos coordenadores e todos os funcionários das unidades de conservação por proporcionarem conforto e segurança durante as viagens a campo.

A todos os companheiros do Laboratório de Ecologia Vegetal: Ana Cláudia, Anayra, Fernando, Larissa, Luciano, Ludmila, Luis Francisco, Michele, Monise, Nirélcio, Pamela, Sergio e Vanessa pela ajuda inestimável em campo.

Ao Luis Francisco M. Coelho (Mafalda) pela análise preliminar das métricas das paisagens e, em especial, pela sua generosidade, por compartilhar seus conhecimentos e experiências, que foram fundamentais para a execução deste projeto e por viabilizar grande parte do trabalho de campo.

Aos professores e companheiros da disciplina de Ecologia de Campo da Mata Atântica, liderados pelo Prof. Glauco, por acrescentarem muito à minha formação acadêmica.

Aos professores Paulo Inácio, Alexandre e Rodrigo por me apresentarem ao maravilhoso mundo do R.

À Ana Carla M.M. Aquino, por ter cultivado em mim a paixão pelas aves.

Aos amigos Pedro, Simeão e Lívia, que continuaram me apoiando mesmo após dura separação.

Ao meu pai, pelo apoio e compreensão incondicionais, e à minha mãe, companheira de campo exemplar, pelo incentivo nos momentos difíceis, e à qual devo horas valiosas de observação. 


\section{Índice}

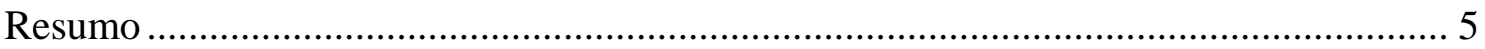

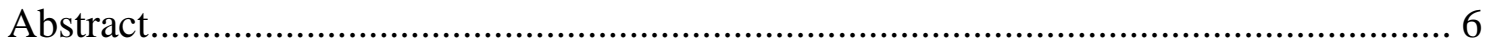

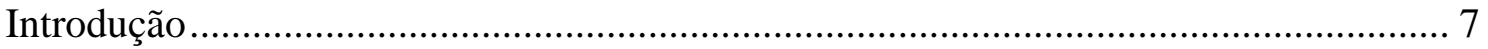

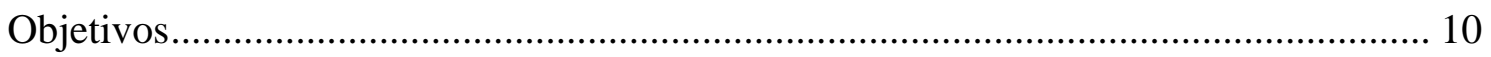

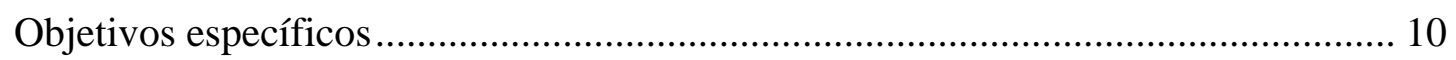

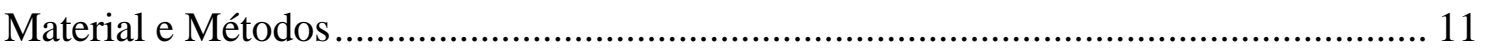

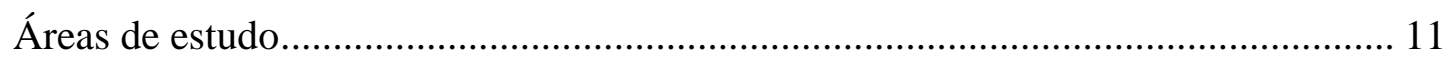

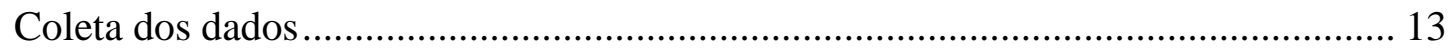

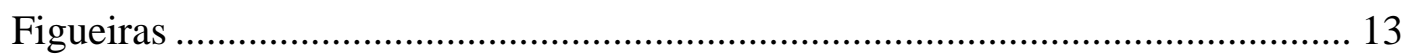

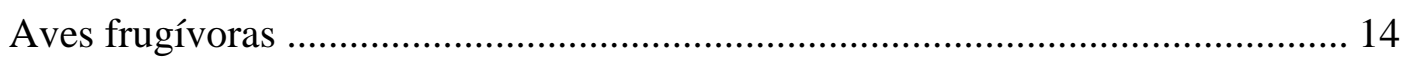

Frugivoria e dispersão de sementes ................................................................ 14

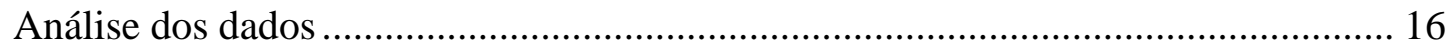

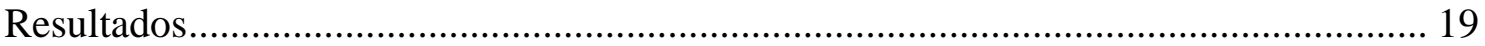

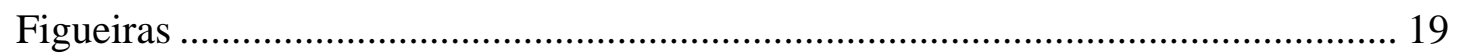

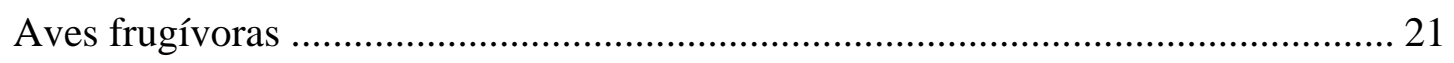

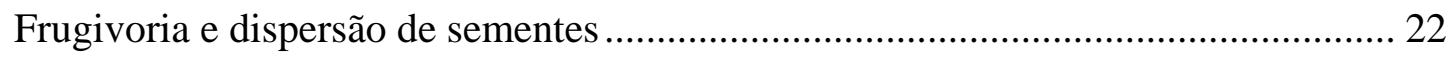

Frugivoria e fragmentação ....................................................................................... 30

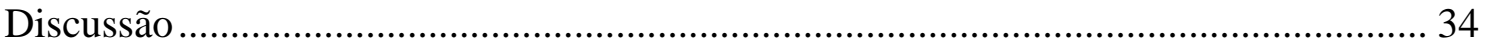

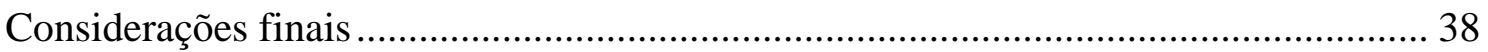

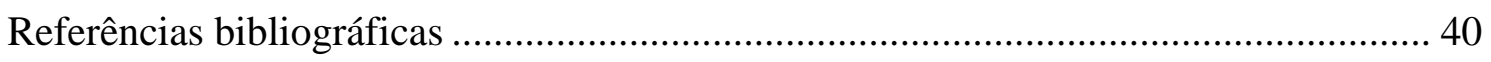

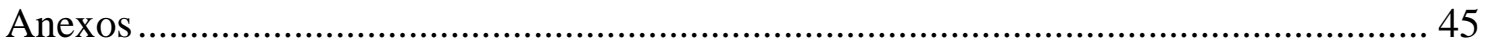




\section{Resumo}

Ficus (Moraceae) é o gênero mais importante para animais frugívoros nas florestas tropicais, considerado um recurso-chave durante períodos de escassez de frutos. Esses animais dispersam suas sementes e contribuem para a manutenção das populações de figueiras. A perda de hábitat e a fragmentação da paisagem podem afetar a sobrevivência de populações e a composição de comunidades e suas interações. Os objetivos deste trabalho foram (1) comparar a frugivoria e a dispersão de sementes por aves frugívoras entre espécies de Ficus encontradas em remanescentes de Floresta Estacional Semidecidual e (2) testar se a perda de hábitat influencia a frugivoria e dispersão de sementes dessas árvores. Estudamos três áreas de reservas florestais no Estado de São Paulo, sudeste do Brasil, com diferentes áreas e nível de fragmentação da paisagem: Parque Estadual do Morro do Diabo (33.845 ha), Estação Ecológica dos Caetetus (2.176 ha) e Estação Ecológica de Ribeirão Preto (180 ha). Ao longo de 443 h de observação árvore-focal, registramos todas as espécies de aves frugívoras se alimentando de figos e estimamos a taxa de remoção de figos e sementes. Como nossos dados não se adequaram a métodos estatísticos tradicionais, utilizamos a reamostragem por bootstrap para estimar os intervalos de confiança das taxas de remoção e dispersão de sementes e testar as diferenças entre as espécies de figueira e as áreas de estudo. Trinta e duas espécies de aves foram observadas consumindo figos de seis espécies de Ficus. As figueiras que apresentam figos verdes, de tamanho médio ou grande, foram consumidas por uma boa variedade de espécies, mas apenas uma das aves de cada assembléia foi responsável pela remoção da maior parte dos figos. Ficus luschnathiana, com figos pequenos e vermelhos quando maduros, foi consumida de forma mais equitativa pelos seus visitantes, e apresentou taxa de dispersão de sementes significativamente maior que as demais espécies. A fragmentação reduziu a remoção de figos e sementes de F. citrifolia. Ficus eximia não demonstrou nenhum padrão claro, uma vez que só teve um consumo expressivo em um microhábitat específico, não incluído na análise da fragmentação. No fragmento menor, aves de grande porte, consideradas bons dispersores de sementes, não foram encontradas e as aves menores e generalistas não compensaram a perda do serviço de dispersão de sementes. Essas espécies de Ficus, no entanto, devem depender mais de morcegos e macacos-prego que das aves no processo de dispersão, e devem inclusive ser beneficiadas pelo aumento na extensão de bordas. Mesmo que essa comunidade de figueiras no fragmento menor não estabeleça uma interação forte com a avifauna, ainda é relevante testar se a baixa densidade de indivíduos de F. luschnathiana é consequencia da ausência de bons dispersores de sementes.

Palavras-chave: Interação animal-planta; Espécie-chave; Dispersão de sementes; Fragmentos florestais; Floresta Estacional Semidecidual. 


\section{Abstract}

Ficus (Moraceae) is the most important plant genus for tropical frugivores and is considered a keystone resource during periods of general fruit scarcity. Frugivorous animals disperse their seeds and contribute for the maintenance of fig trees populations. Habitat loss and landscape fragmentation can affect species survival as well as community composition and their interactions. The goals of this study were (1) to compare the frugivory and seed dispersal by frugivorous birds among Ficus species found in Semideciduous Seasonal Forest remnants and (2) to assess whether habitat loss influences frugivory and seed dispersal of these trees. We studied three natural reserves in São Paulo State, southeastern Brazil, which differ in area and landscape fragmentation: Morro do Diabo State Park (33.845 ha), Caetetus Ecological Station (2.176 ha) and Ribeirão Preto Ecological Station (180 ha). During 443 h focal tree observation, we registered all frugivorous birds eating figs and estimated their fruit removal and seed dispersal. As traditional statistical methods were not suitable for our data, we used bootstrap data resampling to estimate confidence limits of fruit removal and seed dispersal and test for differences between fig trees and forest fragments. A total of 32 bird species were observed consuming figs of six Ficus species. Fig trees bearing green-fruited and medium or large figs were consumed by a great diversity of birds, but showed a dominance of only one species over the others on the fruit removal. Ficus luschnathiana, whose figs are small and red when ripe, was more equally consumed by all visitors and had significantly more seeds dispersed per hour than the other species. Fragmentation reduced fruit removal and seed dispersal of F. citrifolia. Ficus eximia did not show a clear pattern, once it was only highly consumed by birds in a specific microhabitat not included on the fragmentation analysis. The effect upon other Ficus species remains to be tested. In the smallest forest remnant, large-bodied birds, considered highquality seed dispersers, cannot be found anymore and small and generalist birds are not able to compensate for this loss on seed dispersal service. These Ficus species, however, may depend more upon bats and capuchin monkeys than on birds for seed dispersal, and may even benefit from the increase in extension of forest edges. Even if this Ficus community as a whole does not seem to interact with birds, it remains relevant, though, to test whether F. luschnathiana's low density in the smallest fragment is due to the absence of good seed dispersers.

Keywords: Animal-plant interaction; Keystone species; Seed dispersal; Forest fragments; Semideciduous Seasonal Forest. 


\section{Introdução}

Os frutos das figueiras, plantas pertencentes ao gênero Ficus (Moraceae), fazem parte da dieta de mais espécies de animais que qualquer outro gênero de árvore tropical (Janzen 1979, Bleher et al. 2003), incluindo 10\% das espécies de aves e 6\% das espécies de mamíferos de todo o mundo (Shanahan et al. 2001). As aves são o grupo que mais se destaca no consumo desses frutos, com 9.672 espécies, 2.057 gêneros e 54 famílias distribuídas no Velho Mundo e na região Neotropical (Shanahan et al. 2001).

As características fenológicas das figueiras favorecem o consumo de figos por esses animais vertebrados. Ao longo do ano, observa-se uma assincronia na produção de frutos entre espécies e inclusive dentro das populações de Ficus. Em um mesmo indivíduo, essa produção é sincrônica, de forma que, em um dado momento, a maior parte dos frutos encontra-se no mesmo estágio de amadurecimento (Lambert \& Marshall 1991, Compton et al. 1996). Esse padrão assegura a reprodução cruzada das figueiras, pois dá às suas vespas polinizadoras uma fonte contínua de hospedeiros potenciais (ver Compton et al. 1996 para mais detalhes), e tem como consequência a disponibilidade contínua de figos em todas as estações do ano.

Como consequência desse padrão fenológico, em algumas florestas tropicais, as figueiras são consideradas "recursos-chave" por serem capazes de sustentar a comunidade frugívora durante épocas de escassez de recursos alimentares fornecidos por outras espécies vegetais em determinados períodos do ano (Janzen 1979, Terborgh 1986, McKey 1989, Lambert \& Marshall 1991, O’Brien et al. 1998, Peres 2000, Shanahan et al. 2001, Ragusa-Netto 2002, Bleher et al. 2003). A deleção dessas "espécies-chave" poderia resultar na extinção dos frugívoros que dependem de seus recursos durante esses períodos de escassez, e repercutindo em outros aspectos do equilíbrio do ecossistema (Janzen 1979; Lambert \& Marshall 1991).

Há outras características dos figos e da biologia das populações de figueiras que podem explicar tal diversidade de consumidores. O fato de o gênero Ficus apresentar ampla distribuição geográfica nas regiões tropical e subtropical já implica na maior possibilidade de suas espécies estabelecerem interações com uma grande variedade de animais. Além disso, quando maduros, os figos apresentam alto teor de água, carboidratos (Snow 1981) e cálcio (O’Brien et al. 1998), que são nutrientes muito visados pelas aves. Após o desaparecimento do látex, também não possuem substâncias tóxicas, permitindo que mesmo frugívoros sensíveis a certos compostos químico possam utilizá-los como recurso alimentar (Janzen 1979). 
Mesmo o gênero atraindo grande diversidade de vertebrados frugívoros, é possível separar as espécies de Ficus em dois grandes grupos, em função de suas características morfológicas e de seus principais visitantes. Um deles abrange as espécies consumidas predominantemente por morcegos e outros mamíferos, que apresentam geralmente figos grandes (> 15 mm de diâmetro), de coloração verde ou amarela, com cheiro característico e com alta sincronia de amadurecimento. O outro grupo inclui aquelas figueiras com figos pequenos $(<10 \mathrm{~mm})$ e numerosos, avermelhados, com pouco odor, e com certa assincronia no desenvolvimento dos figos, consumidas por aves em geral (Kalko et al. 1996, Korine et al. 2000). Na região Neotropical, a sobreposição das espécies de figueiras incluídas na dieta desses dois grupos de animais foi pequena (Korine et al. 2000).

A maior parte desses vertebrados, com exceção de psitacídeos e alguns columbídeos, podem agir como dispersores das sementes de Ficus e outras plantas zoocóricas. Dentre as vantagens existentes na dispersão de sementes estão a diminuição da competição intraespecífica e da herbivoria sob a planta-mãe, o aumento do recrutamento, com a chegada de sementes a uma maior diversidade de locais, e o aumento do sucesso de germinação e estabelecimento, no caso de espécies que necessitam de um tratamento ou de locais muito específicos para se desenvolver (Howe \& Smallwood 1982, Willson \& Traveset 1992). Esta última característica pode ser exemplificada pelas espécies de figueiras hemiepífitas (na região Neotropical, pertencentes à seção Americana), que iniciam o seu desenvolvimento sobre uma planta suporte e depois lançam suas raízes até o solo (Putz \& Holbrook 1989). O padrão e a intensidade da dispersão de sementes podem influenciar as estruturas genética e demográfica das populações vegetais (Hamrick \& Godt 1996).

Para que uma ave frugívora seja considerada uma boa dispersora, seu método de alimentação, sua digestão, e a deposição das sementes devem ser favoráveis à germinação e ao desenvolvimento das plântulas (Shanahan et al. 2001). Um bom dispersor é aquele capaz de carregar uma grande quantidade de sementes e em seguida mover-se para longe da planta-mãe antes de regurgitá-las ou defecá-las (Kinnaird et al. 1996). As sementes ingeridas por vertebrados geralmente passam ilesas pelo trato digestivo. Testes de germinação mostram que as sementes defecadas pelas aves apresentam maiores taxa e velocidade de germinação que as observadas em sementes que não passaram por esse tratamento (Midya \& Brahmachary 1991; Compton et al. 1996). Frugívoros de grande porte, por serem capazes de engolir frutos e sementes pequenos em grandes quantidades e por serem as únicas capazes de ingerir sementes 
grandes, são geralmente apontados como dispersores ideais da maior parte das plantas (Mikich 2002).

Essa interação, assim como inúmeros outros componentes do ecossistema, pode sofrer alterações em função fragmentação e a perda de habitats florestais (Fahrig 2003). A perda de habitat original e o aumento da quantidade de borda pela fragmentação podem levar a mudanças na composição das comunidades (Murcia 1995), como alterações na ocorrência ou abundância de plantas e aves frugívoras (Schemske \& Brokaw 1981; Restrepo \& Gomez 1998; Restrepo et al. 1999). Espécies de aves generalistas e que frequentam áreas abertas e bordas de mata são mais tolerantes à fragmentação, pois são capazes de alterar sua dieta oportunisticamente nas paisagens alteradas (Galetti \& Pizo 1996, Peh \& Chong 2003). Já aves frugívoras de grande porte são mais suscetíveis à extinção em fragmentos pequenos e isolados por terem geralmente menores taxas reprodutivas, baixas densidades e necessitarem de grandes áreas de forrageamento (Willis 1979, Loiselle \& Blake 1992, Groom et al. 2006).

O sucesso reprodutivo das plantas é negativamente afetado com a diminuição da riqueza e da diversidade de dispersores de qualidade (Wright et al. 2000, Jordano et al. 2006), uma vez que a maior parte das suas sementes passam a se restringir à área sob a planta-mãe e suas imediações (Galetti et al. 2003a). Kirika et al. (2008), por exemplo, testaram diretamente o efeito da fragmentação florestal na interação uma espécie de Ficus e seus frugívoros na África e detectaram uma diminuição significativa no número de espécies frugívoras e na remoção de figos em remanescentes florestais menores e mais degradados. Mesmo em ocasiões que não há alteração ou mesmo o aumento da remoção de frutos em áreas mais degradadas (Farwig et al. 2006), as sementes podem ser depositadas em ambientes menos favoráveis ao seu desenvolvimento, como nas matrizes urbanas e agrícolas (Argel-de-Oliveira \& Figueiredo 1996). Essa deficiência na dispersão de sementes devida à fragmentação do habitat pode ter sérios impactos sobre o ciclo reprodutivo das plantas ornitocóricas (Cordeiro \& Howe 2003).

No caso das figueiras, a diminuição da densidade populacional prejudicaria a sustentabilidade da população de vespas polinizadoras, uma vez que elas dependem de um número mínimo de indivíduos de uma mesma espécie de Ficus para se manterem em determinada área (McKey 1989). O restante da comunidade frugívora também pode ser negativamente afetado caso essas figueiras desempenhem o papel de "espéciechave” na área considerada (Kirika et al. 2008). 


\section{Objetivos}

Comparar a frugivoria por aves em figueiras em três remanescentes de Floresta Estacional Semidecidual situados em paisagens com diferentes níveis de fragmentação no interior do Estado de São Paulo.

\section{Objetivos específicos}

- Comparar entre os fragmentos as assembléias de aves que consomem figos das espécies mais abundantes de Ficus;

- Comparar o consumo de figos entre as espécies de Ficus e entre os fragmentos;

- Avaliar a potencialidade dessas espécies de aves como dispersoras das sementes de Ficus;

- Discutir as possíveis inter-relações (1) das espécies disponíveis de Ficus, (2) das assembléias de aves frugívoras e (3) do nível de fragmentação do habitat; 


\section{Material e Métodos}

\section{Áreas de estudo}

Foram amostrados três remanescentes de Floresta Estacional Semidecidual no interior do Estado de São Paulo, pertencentes a três paisagens com diferentes níveis de fragmentação: Parque Estadual do Morro do Diabo (PEMD), Estação Ecológica dos Caetetus (EEC) e Estação Ecológica de Ribeirão Preto (EERP). O limite da área considerada para o cálculo dos parâmetros foi de 100.000 ha (Tabela 1, Figura 1).

As três áreas estão sujeitas a um clima sazonal, com verão quente e úmido e invero seco, temperatura média anual de 21 a $22^{\circ} \mathrm{C}$. e precipitação média anual entre 1300 e 1500 mm (Faria 2006, Tabanez et al. 2005, Kotchetkoff-Henriques 2003).

Tabela 1. Parâmetros das paisagens (100.000 ha) onde se encontram os remanescentes florestais estudados. PEMD = Parque Estadual do Morro do Diabo; EEC = Estação Ecológica dos Caetetus; EERP = Estação Ecológica de Ribeirão Preto. Fonte: L.F.M. Coelho, dados não publicados.

\begin{tabular}{|c|c|c|c|}
\hline Parâmetros da paisagem & PEMD & EEC & EERP \\
\hline Município & Teodoro Sampaio & Gália & Ribeirão Preto \\
\hline Nível de fragmentação & Baixo & Médio & Alto \\
\hline Cobertura florestal (\%) & 39,8 & 13,6 & 3,9 \\
\hline $\mathrm{N}^{\circ}$ fragmentos / 100000 ha & 120 & 649 & 219 \\
\hline $\begin{array}{l}\text { Área do remanescente amostrado } \\
\text { (ha) e respectiva porcentagem da } \\
\text { cobertura florestal }\end{array}$ & 33.845 & 2.176 & 180 \\
\hline Tempo de isolamento (anos) & 60 & 80 & 120 \\
\hline Uso predominante da matriz & $\begin{array}{c}\text { pastagens e cana- } \\
\text { de-açúcar }\end{array}$ & pastagens e café & cana-de-açúcar \\
\hline
\end{tabular}

O Parque Estadual do Morro do Diabo (PEMD), com 33.845 ha, é hoje a maior reserva de Floresta Estacional Semidecidual do Estado de São Paulo, localizada no extremo oeste do Estado, região conhecida como Pontal do Paranapanema. Ele se encontra na paisagem com o menor número de fragmentos florestais por hectare e a maior porcentagem de cobertura vegetal dentre as paisagens escolhidas, e por isso considerada pouco fragmentada. Os arredores do PEMD são destinados 
predominantemente à pastagem para a criação de gado, o que ocupa pouco mais de 35\% da paisagem (Faria 2006). Além disso, é a área que foi alterada mais recentemente, com a invasão e destruição da então “Grande Reserva do Pontal”, que abrangia quase 150.000 ha de floresta na região, por aliados políticos e grileiros na década de 1940.

A região de Ribeirão Preto, no Nordeste de São Paulo, ao contrário, é muito fragmentada, com muitos remanescentes isolados e de pequenas dimensões, como é o caso da Estação Ecológica de Ribeirão Preto (EERP), de 154 ha que, junto com uma área de mata em propriedade particular adjacente, soma 180 ha. A destruição da maior parte das áreas de mata se iniciou em 1870, quando essas áreas foram convertidas em grandes fazendas de café. Um século depois elas foram substituídas pelo cultivo de cana-de-açúcar após incentivo do governo do Estado, processo que diminuiu ainda mais a cobertura florestal da região. A área urbana e as áreas de cultivo de cana-de-açúcar ocupam hoje cerca de 75\% da terra na região (Kotchetkoff-Henriques 2003).

A Estação Ecológica dos Caetetus (EEC), no centro do Estado, tem 2.176 ha, e a paisagem à qual pertence apresenta valores intermediários dos parâmetros de fragmentação em comparação com as outras duas áreas de estudo. Nesse município, $67,3 \%$ se destinam à pastagem, e 18,7\% à agricultura, com predomínio ainda da cultura do café (Tabanez et al. 2005). Embora não se compare com a área contínua de florestas encontrada no Pontal do Paranapanema, essa região conta com uma ampla drenagem acompanhada de matas ciliares e planícies de inundação, o que aumenta a conectividade estrutural e, provavelmente, funcional entre os remanescentes florestais, atenuando os efeitos da perda de hábitat sobre algumas espécies que são capazes de utilizar corredores de mata na travessia entre fragmentos.

As características dessas três áreas apresentam um gradiente de grande amplitude e de mesmo sentido das variáveis mais importantes para a alteração das comunidades de aves sob o efeito da fragmentação e perda de hábitat: área contínua de hábitat florestal, cobertura florestal e tempo de isolamento da área. Assim, não foi possível separamos aqui os efeitos individuais desses componentes da fragmentação. Na EERP, por exemplo, com a menor área, o maior tempo de isolamento e a menor cobertura florestal na paisagem asseguram um efeito negativo sobre as populações de aves. No PEMD, devido ao menor tempo de isolamento e à grande área contínua de habitat encontra-se a condição mais próxima da Floresta Estacional Semidecidual que cobria todo o interior do Estado de São Paulo. Na EEC, temos uma situação intermediária desse processo. 


\section{Coleta dos dados}

Figueiras

Trilhas, bordas e o interior dos três fragmentos florestais foram percorridos assistematicamente em busca de figueiras em estágio reprodutivo, que foram identificadas (classificação e nomenclatura segundo Berg \& Villavicencio 2004) e georreferenciadas para acompanhamento futuro. Exsicatas de todas as espécies encontradas contendo ramos reprodutivos foram depositadas no herbário da Faculdade de Filosofia, Ciências e Letras de Ribeirão Preto (SPFR). Para caracterização das figueiras, medimos o diâmetro a 1,30 $\mathrm{m}$ do solo (diâmetro à altura do peito - DAP) e estimamos a altura de cada indivíduo, e coletamos 20 figos de cada espécie para determinar o diâmetro e o número médio de sementes por figo.
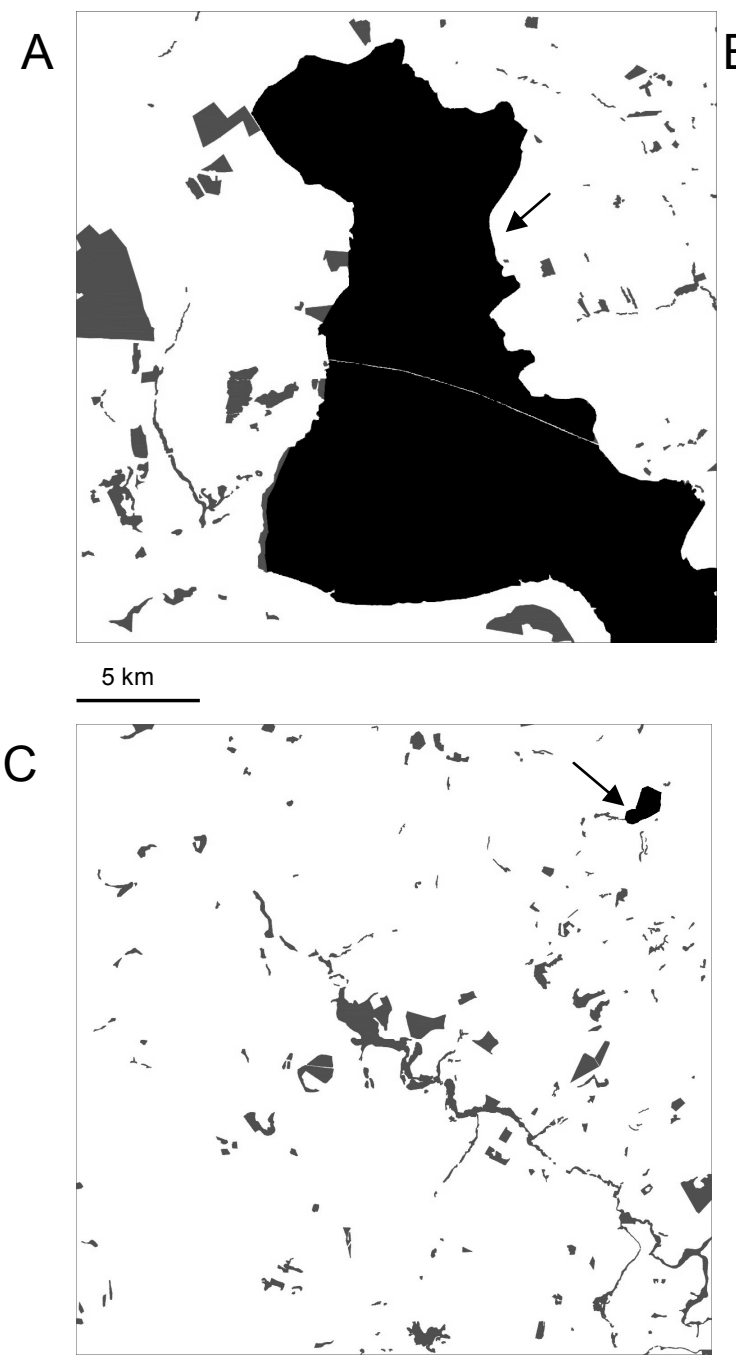

$B$

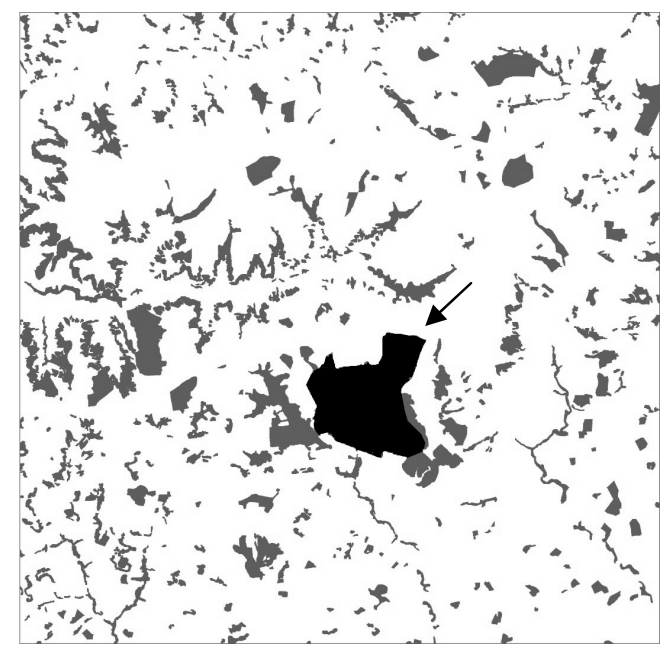

$5 \mathrm{~km}$

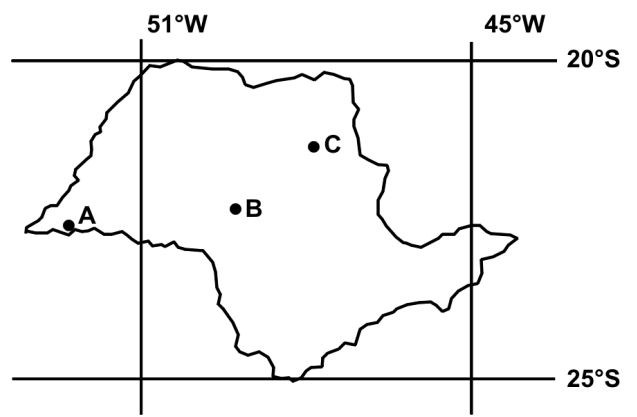

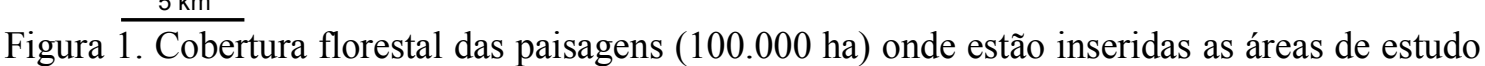
(em preto) e localização no Estado de São Paulo: (A) Teodoro Sampaio (PEMD); (B) Gália (EEC); (C) Ribeirão Preto (EERP). 
Como as figueiras produzem figos assincronicamente ao longo do ano, cada área de estudo foi visitada bimestralmente, no período compreendido entre janeiro de 2008 e março de 2009, para verificar quais árvores apresentavam figos maduros. Amostramos figueiras situadas nos estratos intermediário (com altura entre 4 e $10 \mathrm{~m}$ ) ou superior (com altura maior que $10 \mathrm{~m}$ ) da floresta (Durigan et al. 2000), onde há maior consumo por aves frugívoras (Hasui \& Höfling 1998), e que tinham pelo menos 50\% de sua copa visível a partir de um ponto de observação localizado a aproximadamente $20 \mathrm{~m}$ da base da árvore. Demos preferência para a amostragem das espécies que fossem frequentes nas três áreas, possibilitando a comparação entre os fragmentos.

Aves frugívoras

A fim de descrever o perfil da comunidade de aves de cada área de estudo, definimos uma lista, baseada em levantamentos realizados anteriormente nas áreas de estudo (Willis \& Oniki 1981, Betini 2001, Tabanez et al. 2005, Faria 2006, M.E. Lapate, obs. pessoal), das aves cujas dietas incluem frutos, mesmo que esporadicamente ou em pequena proporção. O hábito alimentar das espécies foi determinado com base em observações de campo e descrições encontradas na literatura (Sick 1997, Piratelli \& Pereira 2002, Rosa 2003, Pizo 2004, Fadini \& De Marco 2004, Pascotto 2006). A nomenclatura e a taxonomia das espécies de aves seguiram o CBRO (2007).

Frugivoria e dispersão de sementes

Utilizamos a metodologia árvore-focal, que consiste na observação da árvore durante o período no qual seus frutos se encontram maduros a fim de registrar todas as espécies que utilizam seus frutos como recurso alimentar (Galetti et al. 2003b). As observações se concentraram no início da manhã (do nascer do sol às 10h30min) e no final da tarde (das 15h30min ao pôr do sol), horários de maior atividade da avifauna. Dias chuvosos não foram incluídos na amostragem. No total, amostramos 443 horas de observação árvore-focal (22 safras) de seis espécies de Ficus (Tabela 2).

As aves que eram observadas removendo figos foram identificadas com auxílio de binóculos 8 x 30 e guias de campo (Souza 1998, Sigrist 2007). Para cada visita de uma espécie de ave à figueira, registramos: o tempo transcorrido após o início da observação (agrupado em intervalos de 1 h), o número de indivíduos de cada bando, a duração (em minutos) da visita a partir da remoção do primeiro figo, o número de figos removidos 
pelo indivíduo visitante ou por um indivíduo do casal ou bando monoespecífico durante toda a visita e a fração consumida de cada figo removido.

Tabela 1. Número de horas de observação árvore-focal e de safras amostradas (entre parênteses) de cada espécie de Ficus nas áreas de estudo.

\begin{tabular}{lcccc}
\hline Espécie de Ficus & PEMD & EEC & EERP & Total \\
\hline Ficus citrifolia & $32,8(2)$ & $51,9(2)$ & $65,0(3)$ & $149,7(7)$ \\
Ficus crocata & $52,0(2)$ & - & - & $52,0(2)$ \\
Ficus eximia & $35,6(3)$ & $74,1(3)$ & $34,8(2)$ & $144,4(8)$ \\
Ficus insipida & - & $27,5(1)$ & $13,9(1)$ & $41,4(2)$ \\
Ficus luschnathiana & $20,1(1)$ & $11,1(1)$ & - & $31,2(2)$ \\
Ficus obtusifolia & - & $24,5(1)$ & - & $24,5(1)$ \\
\hline Total & $140,4(8)$ & $189,1(8)$ & $113,7(6)$ & $443,2(22)$ \\
\hline
\end{tabular}

Como os figos possuem um número elevado (> 50) e variável de pequenas sementes, não foi possível determinar o número exato de propágulos ingeridos durante as visitas. O figo inteiro foi, então, utilizado como parâmetro na estimativa da dispersão das sementes. Registramos a proporção ingerida de cada figo removido, aplicando as seguintes frações: 1 (ingerido inteiro), 2/3 (ingestão de mais da metade do figo), 1/3 (ingestão de menos da metade do figo), 0 (descarte total do figo ou destruição das sementes). A média dessas frações estima a proporção de sementes potencialmente dispersas (a partir daqui denominada “probabilidade de dispersão”), e representa parcialmente a qualidade do processo de dispersão das sementes. Outros processos importantes da dispersão que ocorrem após a ingestão das sementes, como o efeito do trato digestivo sobre a viabilidade das sementes e a deposição das mesmas em locais favoráveis para a germinação e desenvolvimento das plantas, não foram avaliados neste estudo.

Para associarmos o tamanho dos figos e a largura do bico com a probabilidade de dispersão (ver análise de dados), medimos o diâmetro de 20 figos de cada espécie de Ficus (precisão de 0,1 mm). Medimos também a largura do bico (distância entre as comissuras na base do bico) de 20 exemplares de cada espécie de ave frugívora observada ao longo do estudo (precisão de 0,1 mm). Os espécimes utilizados pertencem ao Museu de Zoologia da Universidade de São Paulo (MUZUSP), e foi dada preferência àqueles coletados no interior do Estado de São Paulo para evitar variações morfométricas entre populações de regiões distintas. 
Para cada espécie de ave, em cada uma das espécies de Ficus estudadas, calculamos o número médio de figos removidos por visita de cada indivíduo, tomando como base apenas visitas completas, ou seja, aquelas nas quais o mesmo indivíduo foi acompanhado durante toda a visita. Multiplicamos esse valor pelo número total de indivíduos de cada espécie se alimentando durante as observações. Dividindo esse valor pelo esforço amostral, obtemos a taxa de frugivoria, expressa em figos removidos. $\mathrm{h}^{-1}$ :

Taxa de Frugivoria $=\frac{n^{\circ} \text { figos removidos }}{\text { visita }} \times n^{\circ}$ indivíduos $\times \frac{1}{\text { horas }}$

A taxa de dispersão, expressa também em figos “dispersos”. ${ }^{-1}$ foi calculada multiplicando as respectivas taxas de frugivoria pela probabilidades de dispersão:

Taxa de Dispersão = Taxa de frugivoria $\times$ Probabilidade de dispersão

\section{$\underline{\text { Análise dos dados }}$}

Os dados foram analisados inicialmente por métodos exploratórios (Ellison 1993), objetivando a descrição dos resultados e comparações visuais entre as espécies de Ficus e entre as áreas de estudo.

Para detectarmos se as comunidades de aves das áreas de estudo seguem um padrão aninhado (relação na qual as espécies observadas em uma área menos rica representam um subgrupo do total de espécies que ocorrem em outra área, Patterson 1987), fizemos uma análise visual comparando a composição das três comunidades. Restringimos a comparação às espécies cujas distribuições espaciais conhecidas (baseadas em Sigrist 2005) incluem as três áreas de estudo, evidenciando, por exemplo, a extinção seletiva de algumas espécies nas áreas mais fragmentadas.

Comparamos o compartilhamento de espécies nas assembléias de aves e a importância relativa de cada uma delas no consumo de figos entre as figueiras por meio de uma representação gráfica da rede trófica observada. Utilizamos o pacote estatístico “bipartite” (Dormann et al. 2008) do programa estatístico R (Crawley 2005).

Como o esforço amostral foi medido em horas de observação, a fim de testar se as taxas de frugivoria e dispersão diferiram entre as espécies de Ficus e entre as áreas de estudo, geramos intervalos de confiança para essas variáveis por meio da reamostragem de bootstrap (Manly 1997). Foram consideradas diferentes as taxas de frugivoria ou dispersão cujos intervalos de confiança não se sobrepuseram. 
Para estimar o número total de figos removidos em cada hora de observação, estimamos, inicialmente, a remoção por espécie de ave. A remoção por espécie foi calculada, para cada safra, multiplicando-se o número médio de figos removidos por cada espécie de ave em visitas completas pelo número de indivíduos registrados em cada hora de observação. Por fim, somamos o número de figos removidos por todas as aves para obter o número de figos removidos em cada hora de observação.

Para a reamostragem, concatenamos o número de figos removidos em cada hora de observação das safras pertencentes à mesma espécie de Ficus. Desse conjunto de dados, obtivemos 10.000 reamostras por bootstrap (X amostras de tamanho N com reposição, onde $\mathrm{N}$ = número total de horas de observação de cada espécie de Ficus), utilizando o pacote "boot” (Canty \& Ripley 2009) do programa estatístico R (Crawley 2005). Em cada uma das 10.000 reamostras estimamos a taxa de frugivoria (figos. $\mathrm{h}^{-1}$ ), calculando a média de cada uma das reamostras. Assim, a taxa de frugivoria de cada espécie de Ficus foi representada pela mediana, e os limites do intervalo de confiança, pelos 2,5 e 97,5 percentis (incluindo 95\% dos valores centrais das reamostragens) (Manly 1997).

O mesmo procedimento foi aplicado na comparação das taxas de dispersão, multiplicando antes a média do número de figos removidos por visita de cada ave pela sua respectiva probabilidade de dispersão naquela safra.

Uma das árvores de Ficus eximia amostradas na EEC apresentou assembléia de aves e taxa de frugivoria desproporcionalmente maiores que as registradas em todas as outras safras dessa espécie. Nas proximidades dessa árvore há um pomar pertencente à sede administrativa da Estação Ecológica, que pode ter atraído mais aves que o esperado em uma figueira sem outras fontes alimentares em grande quantidade nas áreas adjacentes, como os demais indivíduos amostrados. Ao longo dos resultados serão mostradas as diferenças observadas nas variáveis com a inclusão ou não desse indivíduo para ponderar esse possível efeito antrópico na interação.

Usamos modelos lineares para testar o efeito do tamanho dos figos e a largura do bico das aves sobre a probabilidade de dispersão desses figos. Incluímos apenas os dados cuja probabilidade de dispersão foi baseada na observação de pelo menos quatro figos, uma vez que esse índice é resultado da média de pesos divididos em quatro categorias, evitando, assim, valores extremos baseados em apenas uma observação. As espécies da família Psittacidae não foram incluídas nessa análise por não serem dispersores potenciais, uma vez que destruíram as sementes, independentemente de seu tamanho. Para contornar possíveis interferências nas análises causadas pela relação 
filogenética entre as espécies de aves, a qual poderia levar à dependência dos valores da largura do bico entre si, testamos dois modelos: um deles utilizando os valores observados da interação com as espécies de aves individualmente (pontos não independentes entre si), e outro aplicando a média da largura do bico e a probabilidade de dispersão calculada para as famílias de aves (pontos independentes).

Comparamos a distribuição dos valores medidos de tempo de permanência das aves sobre a figueira após o consumo do primeiro figo com o tempo estimado de retenção do alimento no trato digestivo, baseado na literatura (Schupp et al. 2002, Wütherich et al. 2002). Em passeriformes esse tempo é de aproximadamente 20 minutos, e em aves de grande porte, mais de 30 minutos. 


\section{Resultados}

\section{$\underline{\text { Figueiras }}$}

Nas áreas de estudo encontramos sete espécies de figueiras, sendo seis pertencentes à seção Americana (Ficus citrifolia Mill., F. crocata (Miq.) Miq., F. eximia Schott, F. luschnathiana (Miq.) Miq., F. obtusifolia Kunth, F. trigona L.F.) e uma à seção Pharmacosycea (F. insipida Willd).

Das sete espécies registradas (Tabela 3), F. luschnathiana e F. trigona são as únicas que apresentam figos avermelhados quando maduros. Ficus citrifolia apresenta figos de coloração verde no início da maturação, ficando roxos somente em fase avançada de maturação. No entanto, na maior parte das safras registradas, os figos caíam ou foram consumidos antes de atingir esse estado. A coloração dos figos das demais espécies não se altera muito, permanecendo verde ou amarela mesmo quando totalmente maduros. Ficus luschnathiana é a única espécie com figos pequenos (diâmetro menor que $10 \mathrm{~mm}$ ). Ficus citrifolia, F. eximia e F. trigona têm figos de tamanho médio (com diâmetro entre 10 e $20 \mathrm{~mm}$ ) e F. crocata, F. insipida e $F$. obtusifolia, figos grandes (com mais de $20 \mathrm{~mm}$ de diâmetro). Todos esses figos se desenvolvem nas axilas das folhas e exalam algum odor.

Tabela 3. Características morfológicas dos figos e dos indivíduos das espécies de Ficus que foram acompanhadas ao longo do estudo: cor dos figos maduros; média \pm desvio padrão dos diâmetros médios dos figos e do número de sementes por figo $(\mathrm{n}=20)$; medianas e amplitudes da altura e do diâmetro a 1,3 m do solo (DAP) das árvores.

\begin{tabular}{lccccc}
\hline Espécie de figueira & Cor & $\begin{array}{c}\text { Diâmetro } \\
(\mathrm{mm})\end{array}$ & $\begin{array}{c}\mathrm{N}^{\circ} \\
\text { sementes }\end{array}$ & Altura $(\mathrm{m})$ & DAP $(\mathrm{cm})$ \\
\hline Ficus luschnathiana & vermelho & $9,9 \pm 0,5$ & $103 \pm 94$ & $11(4 \rightarrow 30)$ & $35(10 \rightarrow 260)$ \\
Ficus trigona & $\begin{array}{c}\text { vermelho } \\
\text { verde- } \\
\text { Ficus citrifolia }\end{array}$ & $12,7 \pm 9,2$ & $72 \pm 16$ & $7(4 \rightarrow 12)$ & $25(14 \rightarrow 150)$ \\
amarelado & $16,0 \pm 1,4$ & $112 \pm 72$ & $6(4 \rightarrow 34)$ & $18(5 \rightarrow 84)$ \\
Ficus eximia & $\begin{array}{c}\text { verde- } \\
\text { amarelado }\end{array}$ & $16,5 \pm 4,4$ & $152 \pm 143$ & $15(8 \rightarrow 30)$ & $100(40 \rightarrow 500)$ \\
Ficus insipida & $\begin{array}{c}\text { verde } \\
\text { Ficus obtusifolia }\end{array}$ & $23,1 \pm 2,0$ & $133 \pm 86$ & $19(9 \rightarrow 30)$ & $70(30 \rightarrow 150)$ \\
Ficus crocata & $\begin{array}{c}\text { verde- } \\
\text { amarelado }\end{array}$ & $23,4 \pm 1,8$ & $260 \pm 85$ & $9(5 \rightarrow 30)$ & $40(13 \rightarrow 120)$ \\
\hline
\end{tabular}


As árvores em estágio reprodutivo da maioria das espécies registradas ocupam o dossel nas áreas de floresta alta e se destacam em locais com matas mais baixas e menos densas. Segundo os dados observados, Ficus luschnathiana, F. trigona, F. obtusifolia e F. crocata produzem figos com pouco menos de $20 \mathrm{~cm}$ de DAP. Apenas indivíduos com mais de $35 \mathrm{~cm}$ de DAP de Ficus eximia e $F$. insipida foram observados frutificando. Ficus citrifolia se diferencia das demais pelo seu porte menor, pelo fato de produzir figos com apenas $3 \mathrm{~cm}$ de DAP, e pela alta densidade populacional em bordas de mata. Os raros indivíduos dessa espécie encontrados no interior dos remanescentes eram hemiepífitas estabelecidas a mais de $7 \mathrm{~m}$ de altura.

As comunidades de figueiras nas três áreas estudadas diferiram em relação a sua composição e à importância de cada espécie. Ficus citrifolia foi a espécie com o maior número de indivíduos em todas as áreas (entre 30 e 40\% do total de indivíduos), seguida por F. crocata (24\%) no PEMD, F. insipida (20\%) e F. luschnathiana (20\%) na EEC, ou F. eximia (30\%) na EERP (Figura 2).

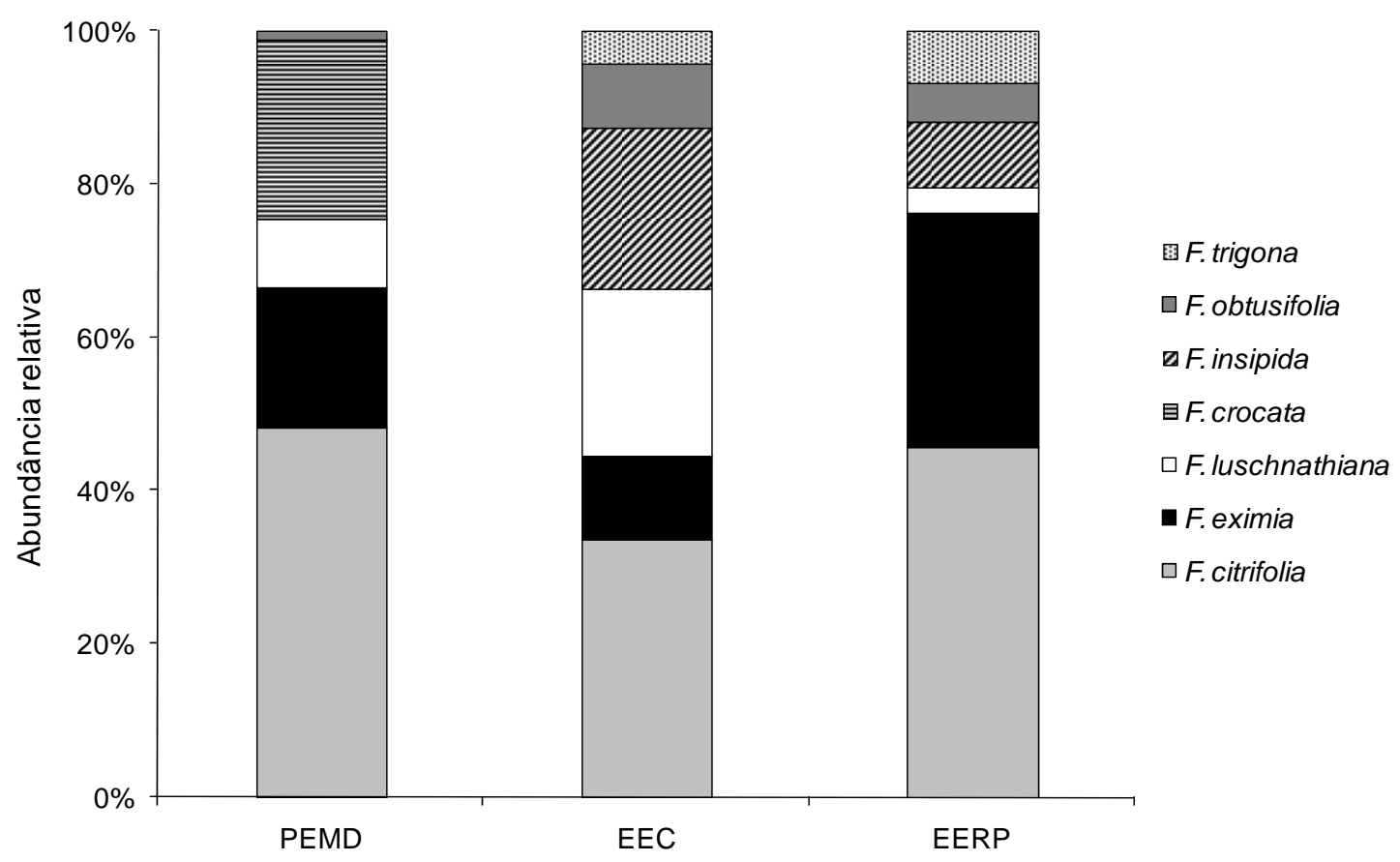

Figura 2. Abundância relativa das espécies de Ficus em cada área de estudo. Número de indivíduos reprodutivos registrados em cada área: $\mathrm{PEMD}=245$; EEC = 119; EERP = 59 .

Levando em consideração a influência das características morfológicas dos figos sobre o seu consumo pelos diversos grupos de frugívoros, os resultados sugerem que a 
interação do gênero Ficus com as aves é mais intensa em Ficus luschnathiana e F. trigona, que possuem figos de coloração avermelhada, e, consequentemente, no fragmento de tamanho médio, onde a abundância relativa dessas espécies foi 2,5 vezes maior que nos outros dois remanescentes.

$\underline{\text { Aves frugívoras }}$

Existem aproximadamente 137 espécies (25 famílias) de aves frugívoras nos fragmentos estudados (Anexo 1). Tyrannidae é a família mais rica dessas três comunidades, mas seus representantes são predominantemente insetívoros, consumindo frutos apenas ocasionalmente (Sick 1997). Os traupídeos, também diversos nas três áreas, além de incluírem grande quantidade de frutos em suas dietas, são dispersores importantes de sementes (Manhães 2003). Nos dois fragmentos maiores há pelo menos seis famílias de aves de médio e grande porte (Corvidae, Cotingidae, Cracidae, Momotidae, Ramphastidae, Trogonidae) que podem apresentar alta taxa de frugivoria e de dispersão de sementes.

A EERP, com a avifauna mais pobre, carece de representantes de algumas famílias de frugívoros de grande porte (Cotingidae, Tityridae, Trogonidae, e outros representantes de Ramphastidae). Penelope superciliaris (Cracidae), uma espécie de grande porte que pode ser encontrada em ambientes degradados (Mikich 2002), não foi registrada na EERP durante o período de estudo, apesar de haver relatos de sua existência na área.

Há certo grau de aninhamento entre as três comunidades de aves frugívoras. Mesmo quando desconsideradas as espécies que não ocorreriam nas três paisagens por limitação biogeográfica, o padrão ainda é bastante claro (Figura 3). Oitenta por cento das espécies que ocorrem no fragmento menor e mais degradado é observada também nos remanescentes de maior área. As demais espécies estão restritas aos fragmentos maiores e mais conservados.

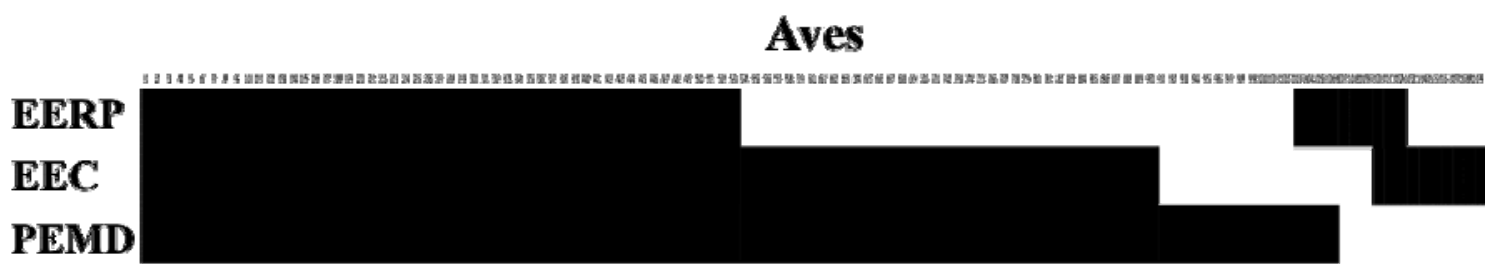

Figura 3. Matriz de ocorrência das espécies de aves frugívoras cuja área de ocorrência biogeográfica inclui as três áreas de estudo. 
Encontramos, portanto, uma comunidade bastante diversa de aves que podem interagir com as espécies de Ficus existentes nos remanescentes florestais, utilizando figos como recurso alimentar em suas dietas.

\section{Frugivoria e dispersão de sementes}

Foram registradas 32 espécies de aves de 15 famílias se alimentando de figos (Tabela 4). Dentre elas, se destacaram as famílias Thraupidae (10 espécies, 31\%), Psittacidae (quatro espécies, 13\%), Ramphastidae e Turdidae (três espécies, 9\% cada). As aves que consumiram a maior diversidade de espécies de figueira foram Thraupis sayaca (cinco espécies), Penelope superciliaris, Turdus leucomelas, Tangara cayana e Dacnis cayana (quatro espécies cada) (Tabela 4). Metade das aves interagiu com duas ou mais espécies de Ficus. Considerando todas as espécies de Ficus, as aves que apresentaram as maiores taxas de frugivoria foram Thraupis sayaca (5,2 figos. $\mathrm{h}^{-1}$; 35\% dos figos removidos), Pyrrhura frontalis (3,0 figos. $\mathrm{h}^{-1}$; 20\%) e Tersina viridis $(1,1$ figos.h $h^{-1} ;$ \%) (Figura 4).

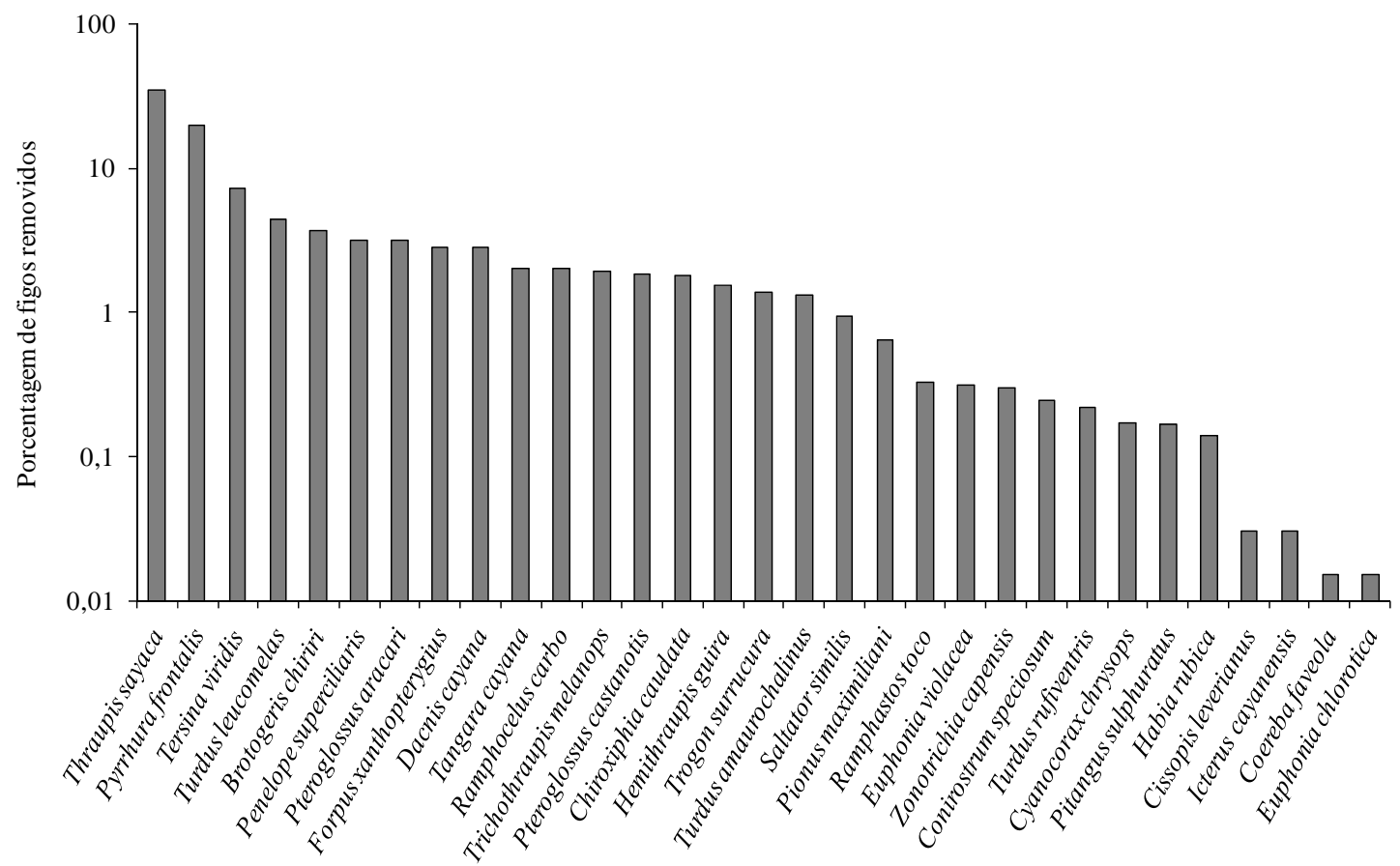

Figura 4. Porcentagem do total de figos removidos por cada espécie de ave. 
Tabela 4. Espécies de aves frugívoras registradas em cada espécie de Ficus e fragmento florestal, e a sensibilidade à perda de habitat segundo Stotz et al. (1996) e Anjos (2006).

Sensibilidade: $\mathrm{a}=$ alta, $\mathrm{m}=$ média, $\mathrm{b}=$ baixa. Fragmentos: $\mathrm{A}=$ PEMD; $\mathrm{B}=\mathrm{EEC}$; $\mathrm{C}=$ EERP.

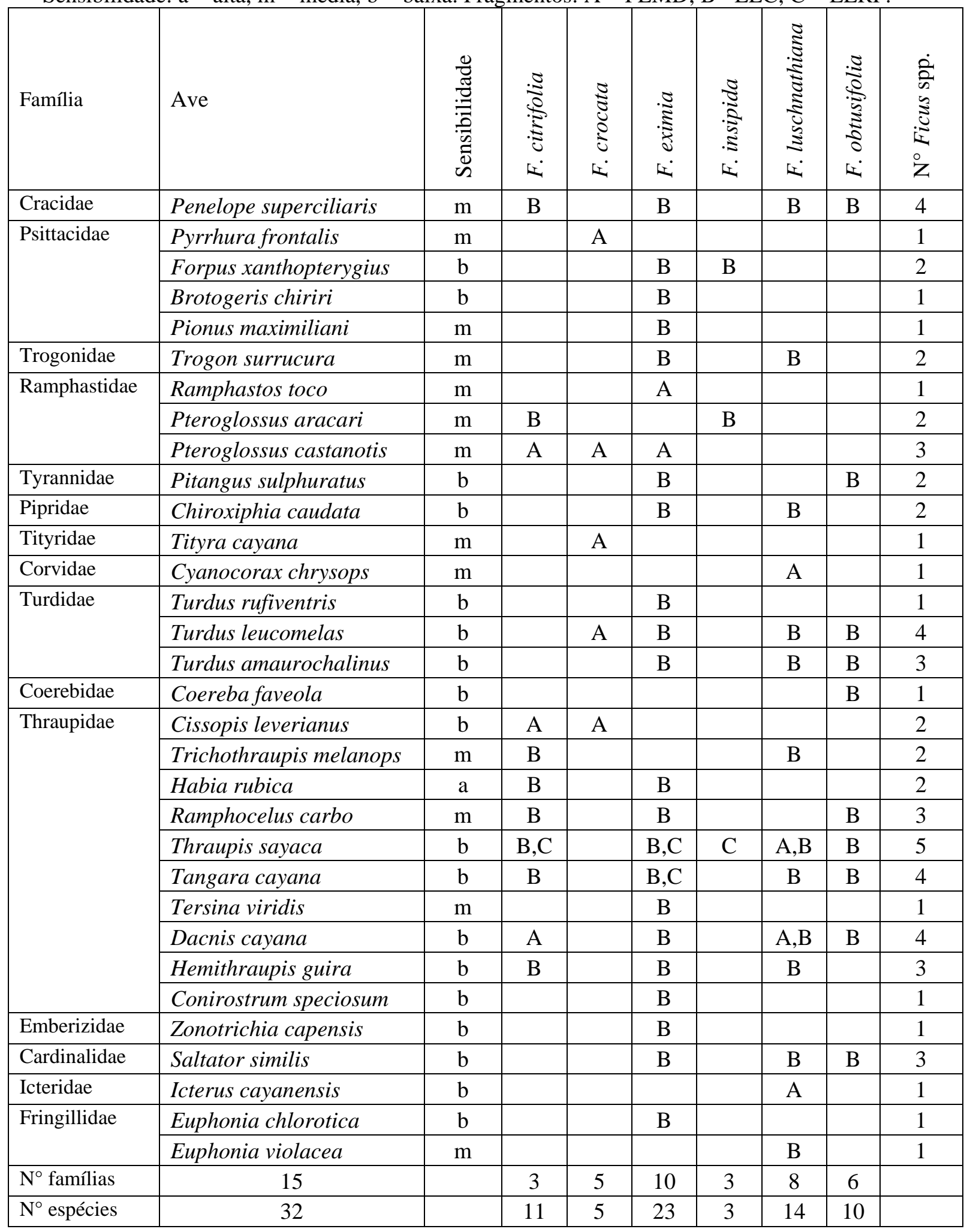


As figueiras com assembléias mais ricas foram Ficus eximia (23 espécies; três sem o indivíduo da sede da EEC) e F. luschnathiana (14 espécies). Ficus crocata e F. insipida foram consumidas por menos de cinco espécies cada. A diversidade taxonômica de aves frugívoras não foi proporcional à riqueza das assembléias. Ficus citrifolia, por exemplo, foi uma das espécies mais bem amostradas, e as 11 espécies de aves registradas em sua assembléia estão incluídas em três famílias: Cracidae (uma espécie), Ramphastide (duas espécies) e Thraupidae (oito espécies). Por outro lado, as figueiras com menor número de espécies de aves visitantes contaram com uma espécie para cada família de ave que estava presente nas observações (Tabela 4).

Todas as figueiras foram consumidas por aves de pequeno e grande porte. Todavia, Ficus crocata e F. insipida, além de terem uma assembléia menos diversa, foram consumidas predominantemente por aves maiores, não-passeriformes (periquitos e araçaris). Por outro lado, a outra espécie de figueira que também apresenta figos de grandes dimensões, F. obtusifolia, foi consumida por 10 espécies de aves, predominantemente passeriformes de pequeno porte. $\mathrm{O}$ fato de essa figueira possuir figos grandes não limitou, portanto, o número de espécies ou a posição taxonômica das aves visitantes.

A coloração verde da maior parte dos figos não limitou o número de espécies de aves frugívoras se alimentando dos figos. Ficus luschnathiana, única espécie amostrada que possui figos vermelhos, compartilhou $80 \%$ das espécies de aves com outras espécies de Ficus (Figura 5) Apenas três aves (Icterus cayannensis, Cyanocorax chrysops e Euphonia violacea) foram registradas apenas em sua assembléia. Ou seja, as outras 29 espécies de aves registradas consumiram também ou exclusivamente figos de cor verde.

No entanto, em todas as espécies que apresentam figos verdes, observamos a dominância de uma ou poucas espécies de aves na remoção de figos: Thraupis sayaca em F. obtusifolia (80\% dos figos removidos) e F. eximia (50\%), Pyrrhura frontalis em F. crocata (90\%), e Pteroglossus castanotis em F. citrifolia (48\%). Em F. luschnathiana, o maior consumidor (Turdus leucomelas) foi responsável pela remoção de $25 \%$ dos figos, fração inferior às das aves dominantes das outras assembléias (Anexo 2). Ou seja, em F. luschnathiana, a importância relativa de cada espécie de ave no consumo de seus figos foi mais bem distribuída que nas assembléias das demais espécies, nas as aves comuns a F. luschnathiana tiveram taxas de frugivoria inferiores. Além disso, essa foi a única figueira visitada constantemente por bandos mistos, 
compostos por Turdus leucomelas, Trichothraupis melanops, Hemithraupis guira, Tangara cayana, Dacnis cayana, Saltator similis e Chiroxiphia caudata.

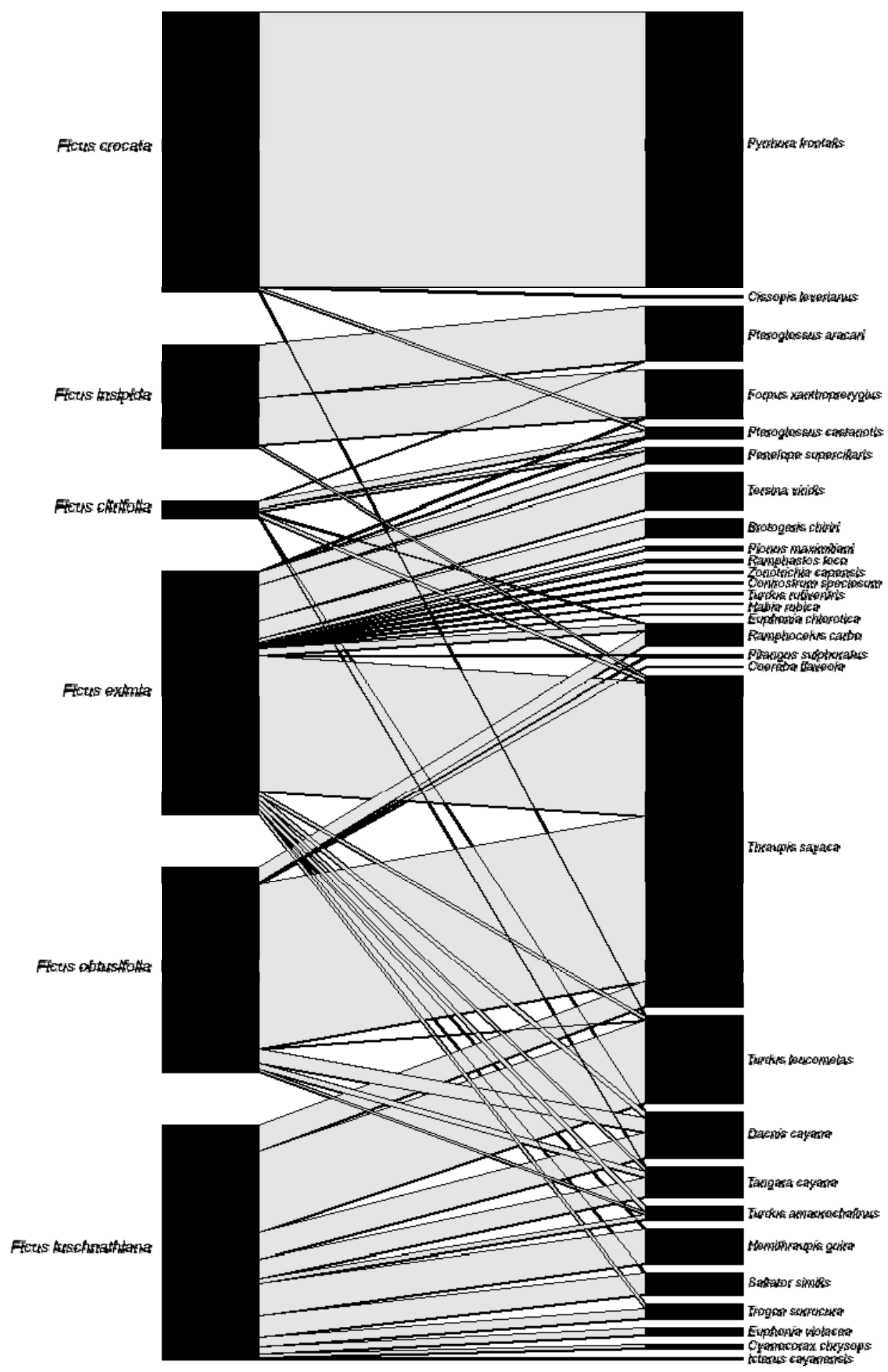

Figura 5. Rede de interação entre as espécies de Ficus e as aves frugívoras. As larguras dos segmentos e ligações são proporcionais às respectivas taxas de frugivoria. 
Os valores e amplitudes das taxas de frugivoria variaram em função da espécie de Ficus (Figura 6). Novamente, não foi identificado nenhum padrão que fosse conseqüência do diâmetro ou da cor dos figos ou do porte das árvores. As figueiras com maiores taxas de frugivoria (Ficus luschnathiana, F. crocata e F. eximia, considerando o indivíduo da sede da EEC) abrangem todos os níveis das características observadas nos figos: figos pequenos, médios e grandes, vermelhos ou verdes. Ficus citrifolia, F. insipida e a maior parte dos indivíduos de F. eximia tiveram menos de 20 figos removidos por hora de observação. No caso específico de F. citrifolia, o menor consumo era esperado pelo menor porte da árvore.

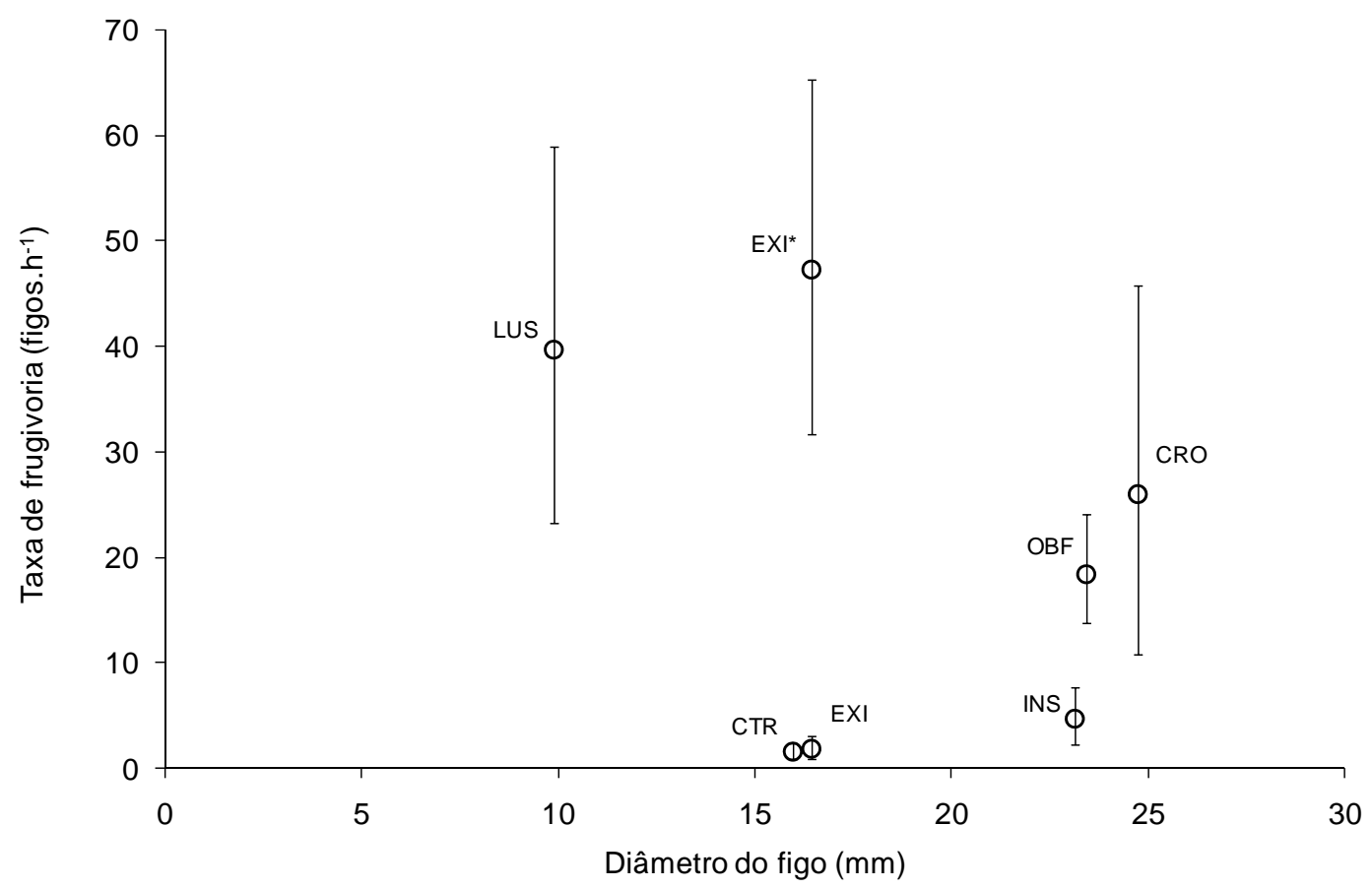

Figura 6. Taxa de frugivoria total de cada espécie de figueira. Os valores centrais representam as medianas, e as barras, os limites que incluem 95\% dos valores reamostrados por bootstrap (ver Material e métodos). CTR = Ficus citrifolia; $\mathrm{CRO}=$ Ficus crocata; EXI = Ficus eximia; INS = Ficus insipida; LUS = Ficus luschnathiana; OBF = Ficus obtusifolia.$(*)$ Taxa de frugivoria de Ficus eximia incluindo safra da sede da EEC.

A maceração foi o comportamento alimentar mais frequente durante o consumo dos figos. Esse comportamento, no entanto, diminui a quantidade de sementes ingeridas pelas aves, diminuindo a sua contribuição na dispersão de sementes. As únicas aves que foram observadas engolindo figos inteiros foram Pteroglossus spp., Trogon surrucura, Penelope superciliaris e Turdus spp. As espécies do gênero Pteroglossus, mesmo sendo de grande porte, maceraram figos grandes, mas com um diferencial: ao alcançarem um 
figo, elas foram observadas provando até três ou quatro figos em sequência, sem removê-los, antes de colher um deles em diversas ocasiões.

A probabilidade de dispersão dos figos foi inversamente proporcional ao diâmetro médio do figo (Figura 7) e diretamente proporcional à largura do bico da ave frugívora (Figura 8). Essas duas variáveis foram significativamente correlacionadas à probabilidade de dispersão, tanto usando os valores por espécies $\left(F_{2,39}=21,29\right.$; p < 0,$\left.001 ; R^{2}=0,50\right)$ ou por famílias de aves $\left(F_{2,21}=15,25 ; \mathrm{p}<0,001 ; \mathrm{R}^{2}=0,55\right.$; Figura 8). Em nenhum dos modelos houve interação significativa das variáveis diâmetro do figo e largura do bico.

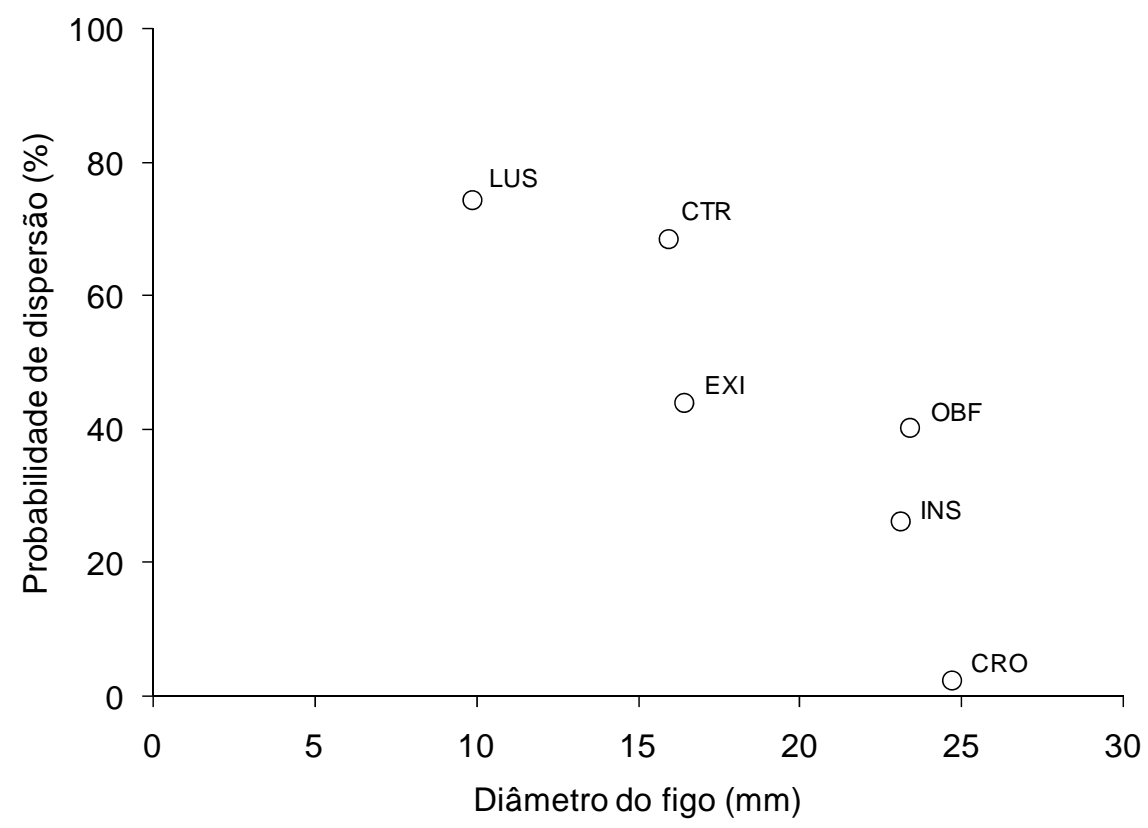

Figura 7. Probabilidade de dispersão de sementes vs. diâmetro do figo em seis espécies de Ficus. Cada ponto representa o valor médio por espécie. CTR $=$ Ficus citrifolia; CRO = Ficus crocata EXI = Ficus eximia; INS = Ficus insipida; LUS = Ficus luschnathiana; OBF = Ficus obtusifolia.

Cerca de 70\% dos figos removidos de Ficus luschnathiana e F. citrifolia foram efetivamente ingeridos pelas aves (Figura 7), graças à capacidade de seus principais consumidores de engolir os figos inteiros. Ficus crocata e F. insipida, cujos principais consumidores foram periquitos, que destruíram as sementes dos figos removidos, tiveram como consequência probabilidades de dispersão inferiores a 30\%. Ficus eximia e F. obtusifolia tiveram mais de 50\% de seus figos removidos por T. sayaca. Essa ave, cujo comportamento alimentar é a de mandibulação do fruto, principalmente daqueles maiores que a abertura de seu bico, ingeriu em média 40\% de cada figo removido, e essa foi a probabilidade de dispersão estimada para essas duas figueiras. Ou seja, a qualidade do serviço de dispersão das figueiras foi diretamente afetada pela limitação 
anatômica e pelos comportamentos das aves frugívoras e pela importância de cada uma delas na remoção dos figos.

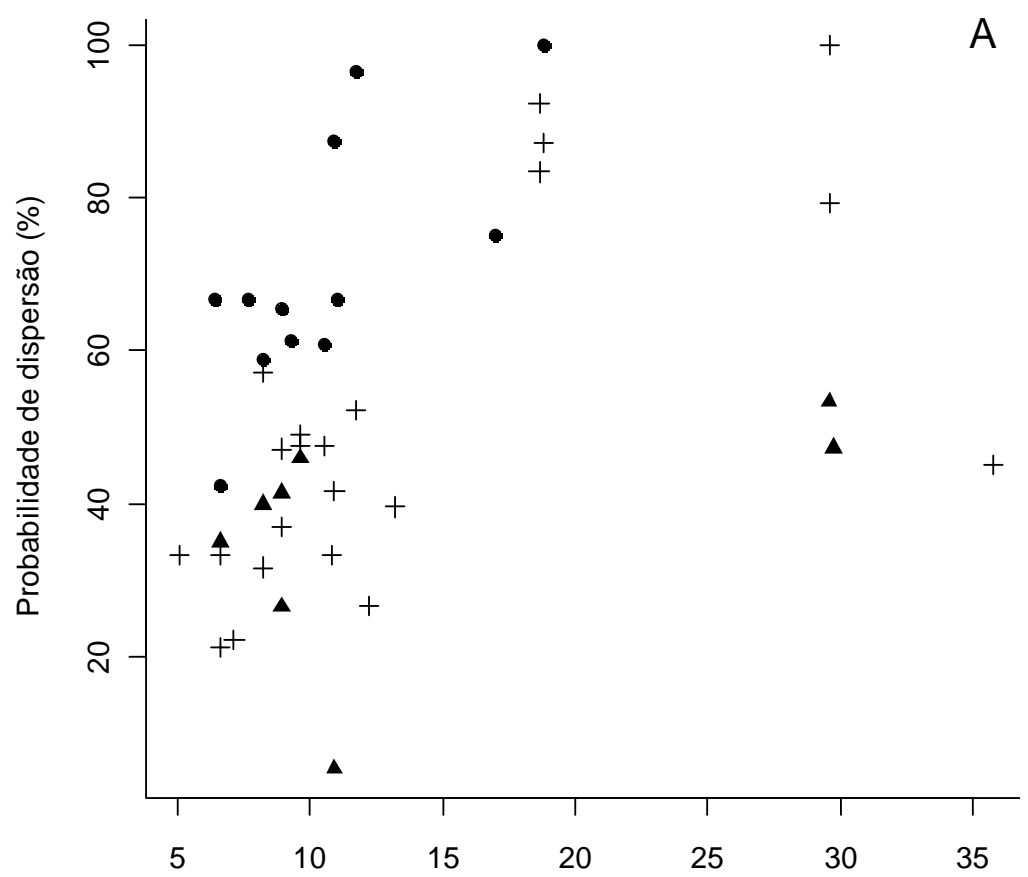

Diâmetro dos figos

- $<10 \mathrm{~mm}$

A 10 a $20 \mathrm{~mm}$

$+\quad>20 \mathrm{~mm}$

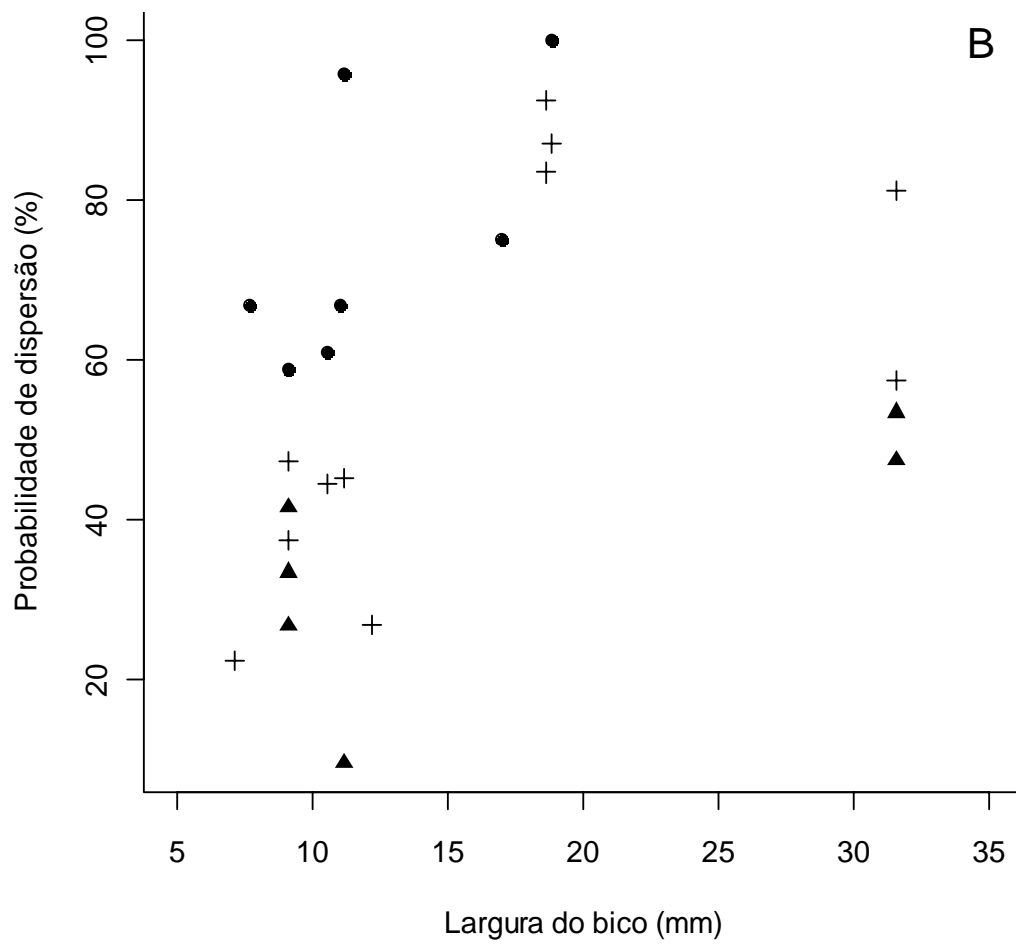

Figura 8. Probabilidades de dispersão de sementes vs. largura do bico da ave. Cada ponto representa o valor médio por espécie (A) ou família (B) de ave. Símbolos diferentes representam classes de diâmetro do figo. 
A maior parte das aves permaneceu menos de 10 min na árvore a pós o consumo do primeiro figo (Figura 9). Em muitas visitas, porém, Tersina viridis permaneceu mais de 30 min sobre a árvore após o consumo do primeiro figo, tempo superior ao tempo de passagem do alimento pelo seu trato digestivo.

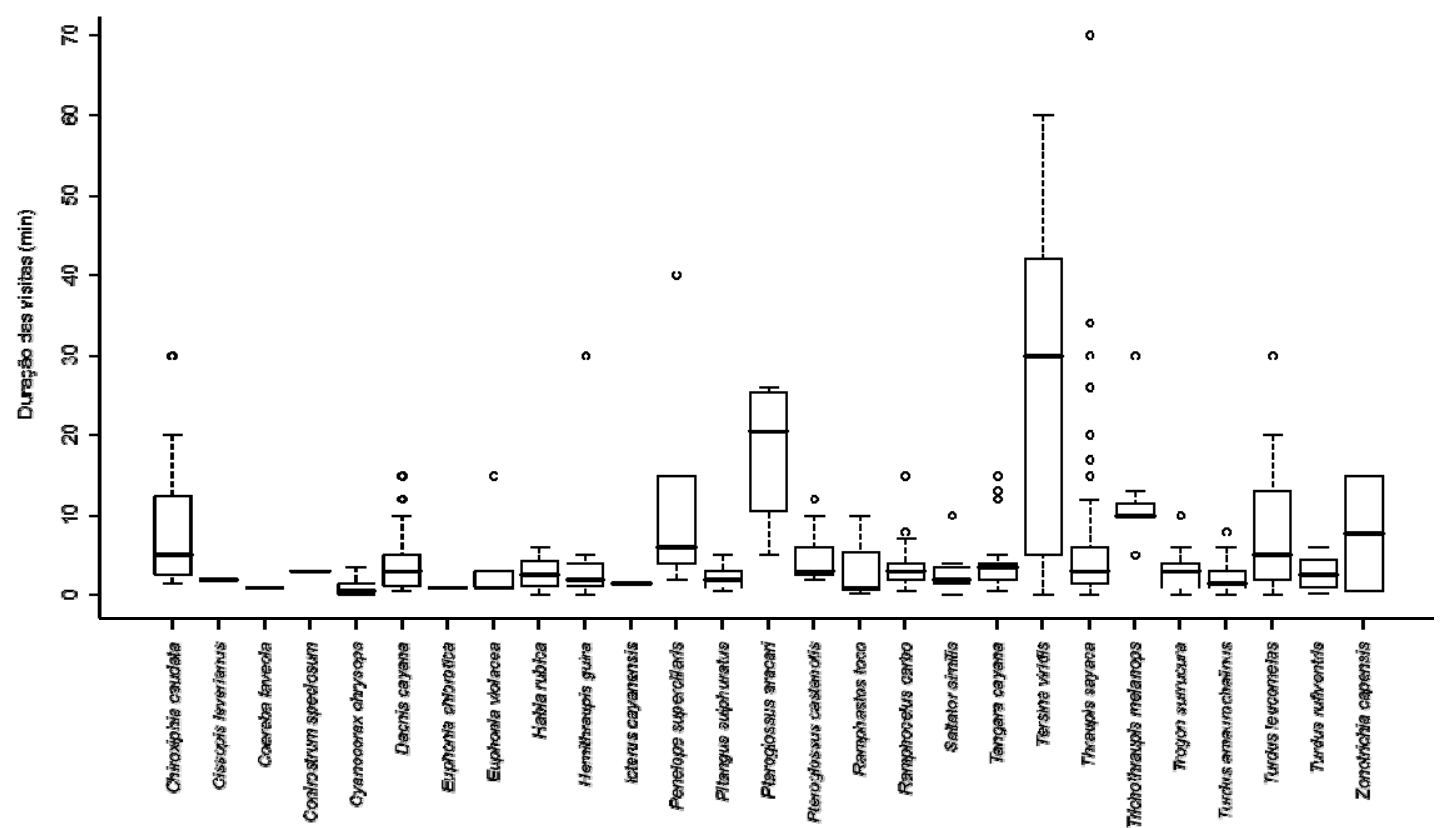

Figura 9. Tempo de permanência das aves potenciais dispersoras sobre a figueira após consumo do primeiro figo. As linhas centrais representam a mediana das medidas, a caixa inclui $50 \%$ dos dados, as linhas tracejadas, 99\% dos dados e os pontos são valores extremos.

Assim, as espécies de aves que mais dispersaram figos considerando todas as figueiras foram Thraupis sayaca (2,1 figos dispersos.h ${ }^{-1}$, 39\% dos figos dispersos), Turdus leucomelas (0,6 figos dispersos. $\left.\mathrm{h}^{-1}, 11 \%\right)$, Tersina viridis e Penelope superciliaris (0,4 figos dispersos. $\mathrm{h}^{-1}, 8 \%$ cada).

As figueiras diferiram mais entre si com relação à taxa de dispersão que à taxa de frugivoria. Ficus luschnathiana teve significativamente mais figos dispersos por hora que qualquer outra figueira, com taxa geral próxima a 30 figos dispersos.h ${ }^{-1}$. As figueiras que, mesmo com altas taxas de frugivoria, foram consumidas por aves que tiveram baixo aproveitamento dos figos removidos, seja pelo descarte de parte das sementes sob a árvore, seja pela inviabilização das sementes por psitacídeos, acabaram apresentando uma taxa de dispersão próxima a zero, como foi o caso de $F$. crocata e $F$. insipida (Figura 10). 


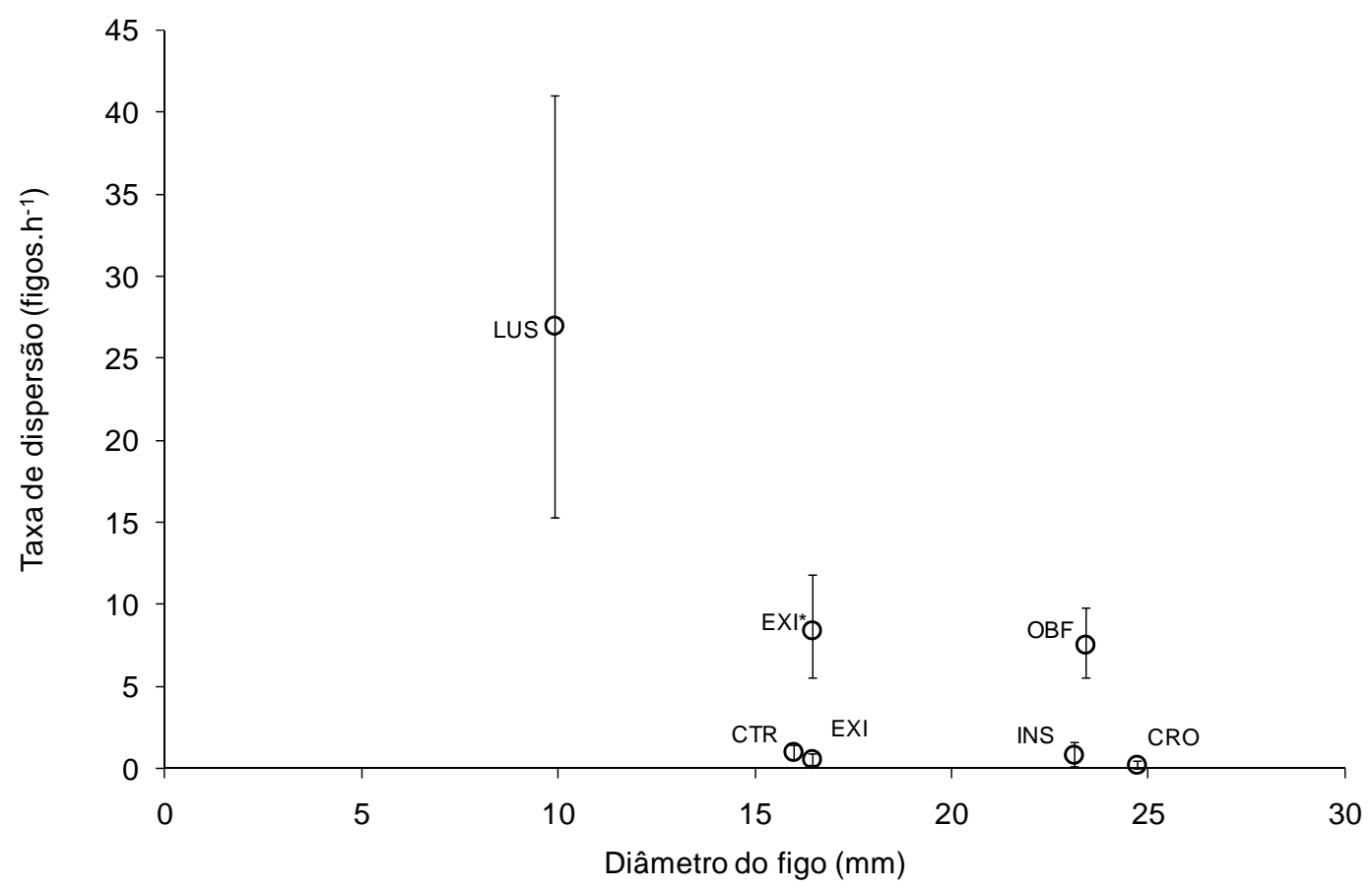

Figura 10. Taxa de dispersão total de cada espécie de figueira. Os valores centrais representam as medianas, e as barras, os limites que incluem 95\% dos valores reamostrados por bootstrap. CTR = Ficus citrifolia , CRO = Ficus crocata EXI = Ficus eximia INS = Ficus insipida ; LUS = Ficus luschnathiana; OBF = Ficus obtusifolia.$(*)$ Taxa de dispersão de Ficus eximia incluindo safra da sede da EEC.

\section{Frugivoria e fragmentação}

O fragmento médio foi a área com o maior número de espécies de aves frugívoras que consumiram figos: 25 das 32 espécies registradas. Isso representa 23\% das espécies de aves frugívoras encontradas nos levantamentos realizados nessa área (Anexo 1), com a presença de várias espécies que ocupam áreas abertas e mais tolerantes à perda de hábitat florestal (Figura 11). Desconsiderando o indivíduo da sede, esse número cai para 16 (14,5\% das aves frugívoras). As demais espécies de aves ocorreram no PEMD, totalizando 10 espécies neste remanescente florestal (8,5\%). A proporção de aves com sensibilidade média e baixa à alteração de habitat no PEMD foi 50\%, semelhante à EEC sem o indivíduo da sede. No menor fragmento (EERP), apenas duas espécies (3,1\%) foram observadas durante as amostragens (Thraupis sayaca e Tangara cayana), ambas bastante tolerantes à perda de hábitat.

O efeito da fragmentação sobre a estimativa da riqueza das assembléias de aves frugívoras de cada espécie de Ficus não foi proporcional à fragmentação e degradação das áreas. O número de espécies de aves em Ficus citrifolia na EEC foi mais de duas vezes maior que nos outros remanescentes, mas ela foi, ainda, consumida por mais aves no PEMD que na EERP (Figura 12). Ficus eximia, quando não considerado o indivíduo 
da sede da EEC, apresentou uma assembléia restrita a, no máximo, três espécie em todas as áreas. A inclusão do indivíduo da sede aumentou em quase dez vezes esse número na EEC.

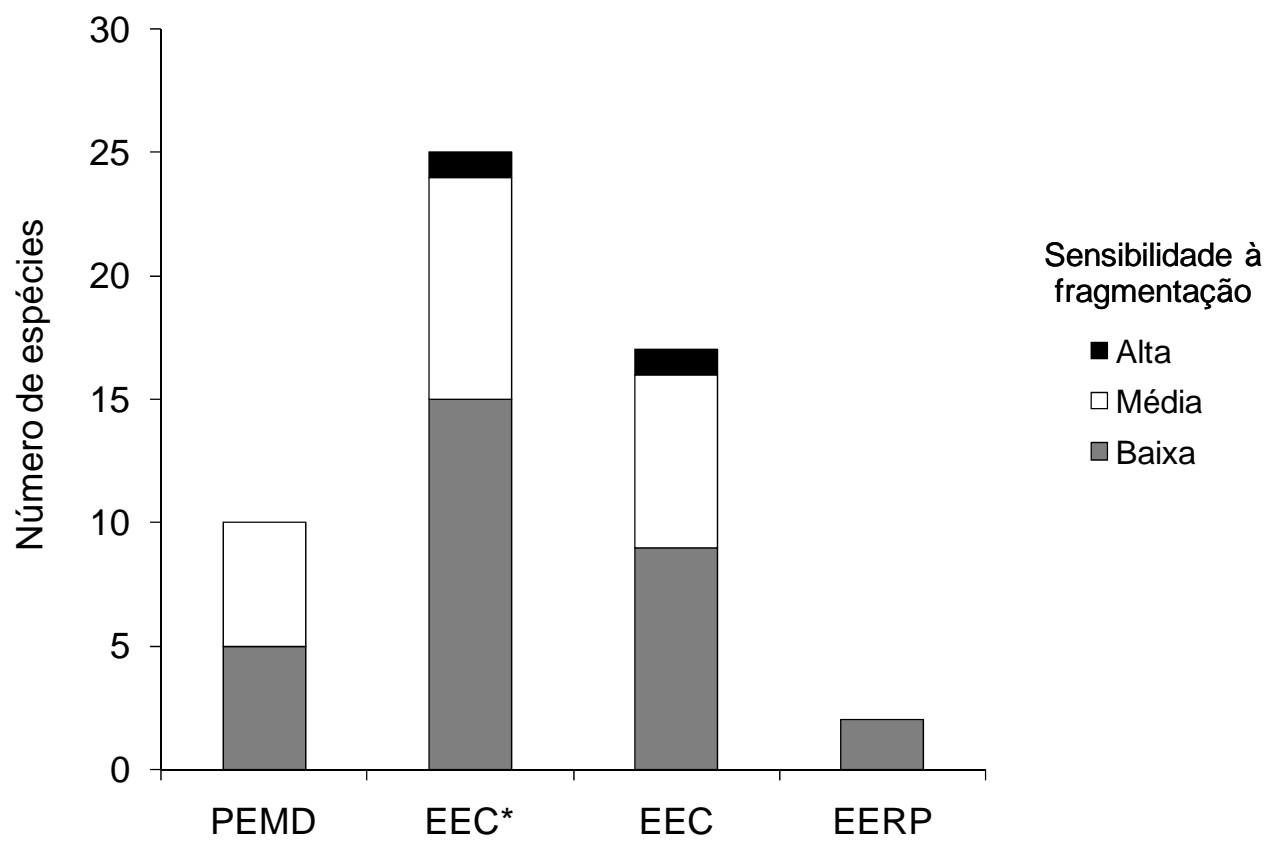

Figura 11. Número de espécies de aves frugívoras observadas em cada área de estudo e sua sensibilidade à fragmentação florestal. (*) Inclui safra da sede da EEC.

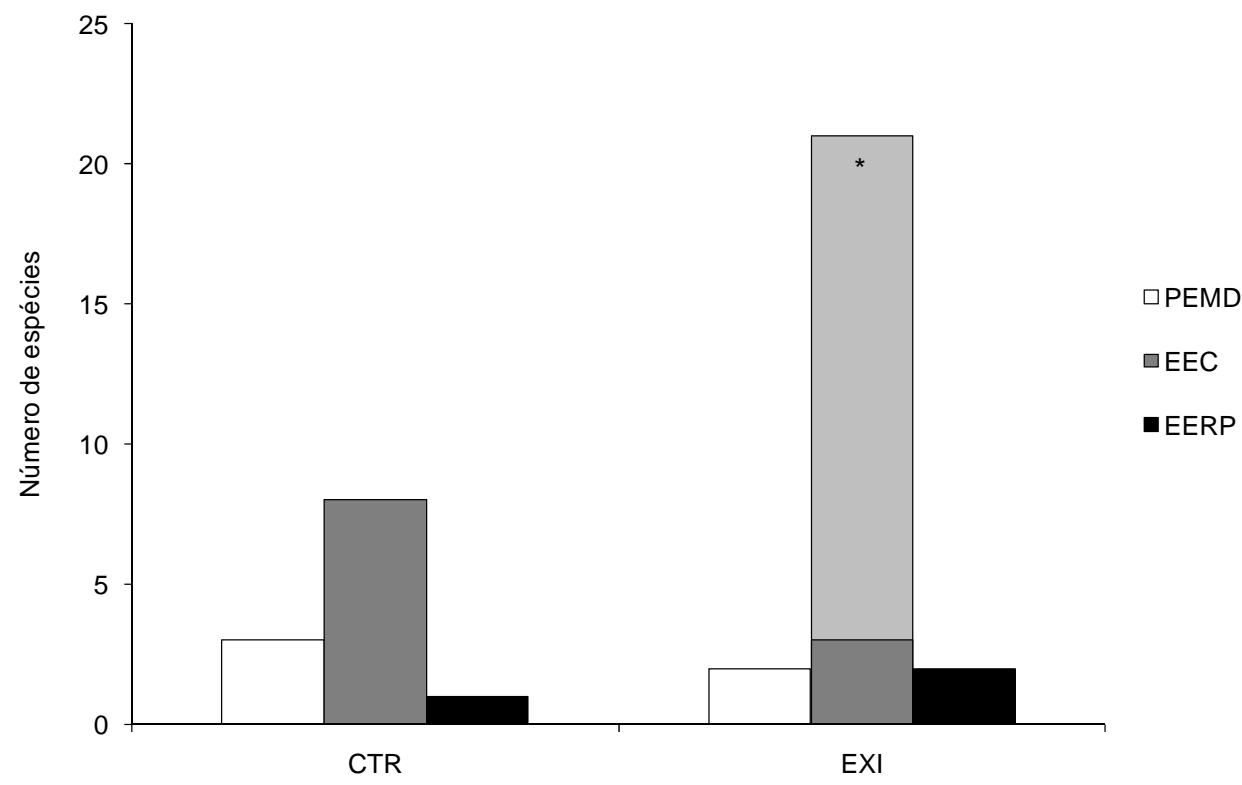

Figura 12. Número de espécies de aves que consumiram Ficus citrifolia (CTR) e F. eximia (EXI) nos três fragmentos. (*) Riqueza e composição incluindo safra da sede da EEC.

Houve uma tendência da taxa de frugivoria de $F$. citrifolia diminuir do maior para o menor fragmento. Os valores não diferiram significativamente entre PEMD e EEC, mas foi menor na EERP em comparação ao PEMD (Figura 13). A frugivoria de $F$. 
eximia, assim como observado com a riqueza de suas assembléias, foi pequena e não se alterou entre as áreas, mas teve significativamente mais figos removidos na EEC quando consideradas todas as safras.

No menor fragmento, apenas Thraupis sayaca consumiu Ficus citrifolia. Nos maiores fragmentos, aves de grande porte como Pteroglossus spp. e Penelope superciliaris foram seus consumidores mais importantes, aumentando a sua probabilidade de dispersão (Figura 14). A probabilidade de dispersão de $F$. eximia diminuiu com a fragmentação, sendo maior no PEMD, onde foi consumida apenas por Ramphastos toco e Pteroglossus castanotis.
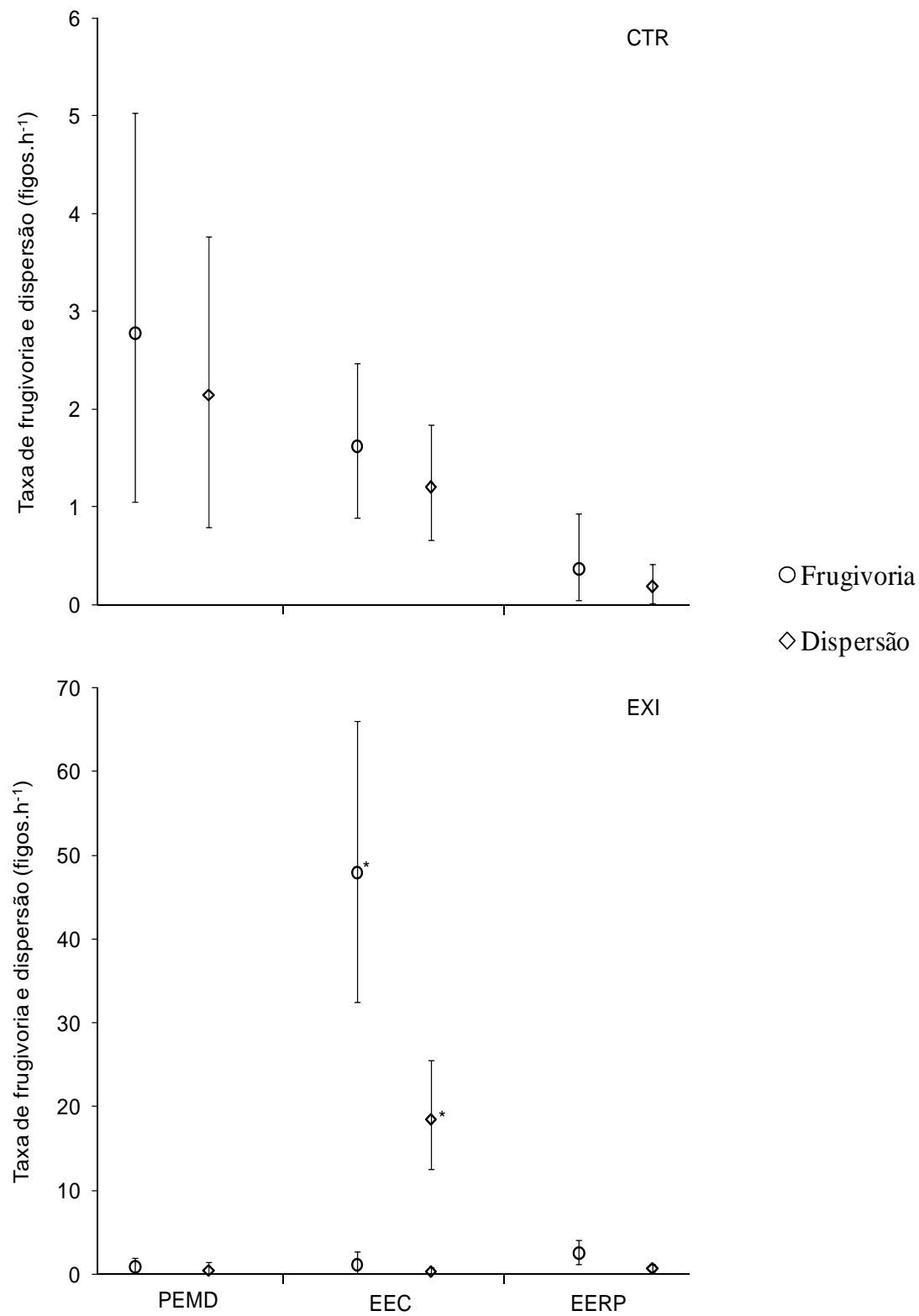

Figura 13. Taxas de frugivoria e dispersão de Ficus citrifolia (CTR) e F. eximia (EXI) em cada fragmento. Os valores centrais representam as medianas, e as barras, os limites que incluem $95 \%$ dos valores reamostrados por bootstrap. $\left(^{*}\right)$ Taxas de frugivoria e dispersão incluindo safra da sede da EEC. 


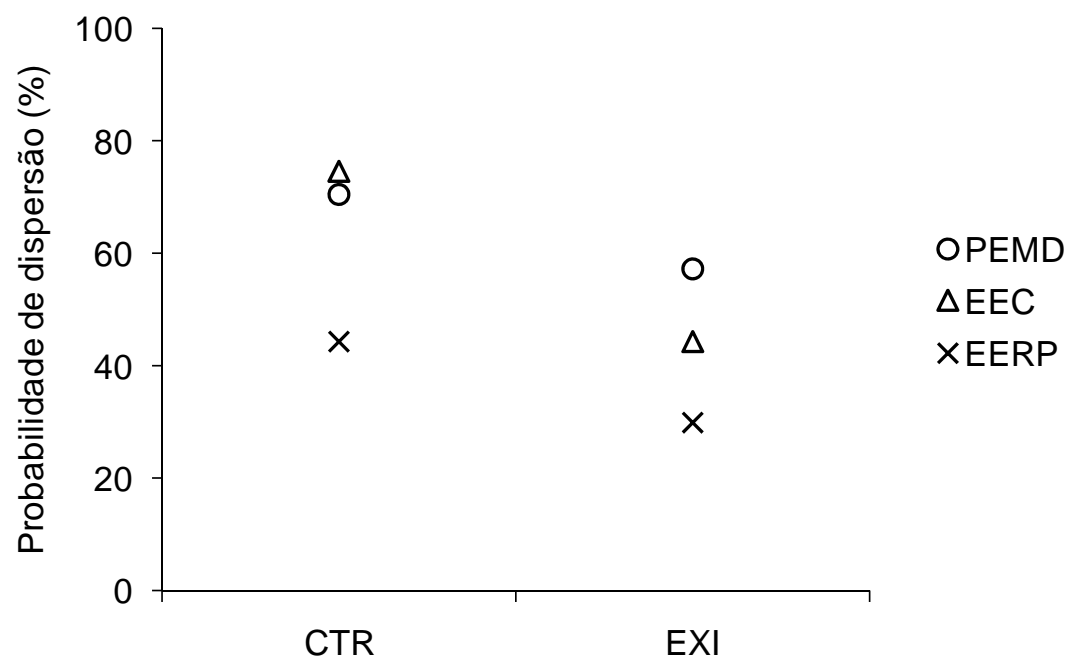

Figura 14. Probabilidade de dispersão de Ficus citrifolia (CTR) e Ficus eximia (EXI) nos três fragmentos.

A dispersão de sementes de Ficus citrifolia na EERP foi significativamente menor que a estimada para os dois outros fragmentos, que não diferiram entre si, mas apresentaram a mesma tendência da taxa de frugivoria de diminuir com a fragmentação (Figura 13). Em F. eximia o padrão encontrado para a taxa de dispersão como resposta à fragmentação foi o mesmo que para a remoção de figos: PEMD e EERP não diferiram e na EEC a taxa só foi significativamente maior quando incluído o indivíduo da sede. 


\section{Discussão}

Nosso estudo mostrou que o gênero Ficus faz parte da dieta de mais de 30 espécies de aves frugívoras de diversos grupos, hábitos e comportamentos na Floresta Estacional Semidecidual. Mostramos também que essa interação pode ser negativamente afetada em áreas com alto nível de fragmentação florestal devido ao desaparecimento de aves sensíveis à perda de hábitat.

As aves frugívoras que se destacaram no consumo e dispersão de figos de mais de uma espécie de figueira foram Thraupis sayaca, Turdus leucomelas, Penelope superciliaris e Pteroglossus spp.. Todas elas removeram grandes quantidades de figos e, com exceção de $T$. sayaca, tiveram alta probabilidade de dispersão de suas sementes. Apenas uma espécie, Tersina viridis, apesar de alta taxa de remoção e probabilidade de dispersão baseada no comportamento alimentar, permaneceu sobre a árvore por quase uma hora, tempo suficiente para as sementes ingeridas dos primeiros figos consumidos serem depositados sob a planta-mãe (Wütherich et al. 2002), diminuindo, portanto, sua contribuição na saída de propágulos.

Dentre as espécies de Ficus amostradas, F. luschnathiana foi aquela que, aparentemente, teve a interação mais forte com a avifauna, apresentando boa diversidade de aves frugívoras, consumo equilibrado entre as aves e alta taxa de frugivoria e dispersão, indicando a procura generalizada de seu recurso pelas aves. As demais figueiras, mesmo quando muito consumidas, tinham a assembléia restrita a poucas aves ou com predominância de uma única espécie. Embora os nossos dados não tenham comprovado o efeito de características morfológicas dos figos sobre cada componente da frugivoria separadamente, o perfil resultante é único e pode, então, ser diretamente relacionado a tais características, como esperado pelo padrão já bem descrito em florestas tropicais e envolvendo diversos níveis filogenéticos, apontando preferência de frutos pequenos e vermelhos (Snow 1981, Pratt \& Stiles 1985, Wheelwright 1993).

Da mesma forma, figos maiores e de coloração verde são frequentemente associados ao consumo e dispersão por mamíferos (Kalko et al. 1996). Observamos, por exemplo, Macacos-prego (Cebus apella) e morcegos (p.ex. Platyrrhinus lineatus, entre outras espécies não identificadas) consumindo figos de todas as espécies de Ficus amostradas em todas as áreas de estudo. Apesar das taxas de frugivoria desses mamíferos não terem sido estimadas, o consumo relativo de figos por eles foi visualmente superior ao consumo pelas aves na maioria das árvores acompanhadas, incluindo um episódio da remoção de $90 \%$ da safra de um indivíduo de Ficus citrifolia 
em uma noite. Essas espécies devem, então, estabelecer uma relação mutualística mais forte com mamíferos que com a avifauna em geral.

Nossos resultados mostraram a vantagem da maleabilidade dos figos para o consumo por diferentes espécies de aves (Janzen 1979): figos grandes não restringiram o consumo por aves de pequeno porte, uma vez que elas foram capazes de retirar pequenos pedaços e ainda ingerir suas sementes de F. obtusifolia. Essa é uma característica que permite o consumo generalizado de figos por animais de diferentes grupos e tamanhos, o que estabelece uma grande diversidade de interações (Shanahan et al. 2001). Do ponto de vista das aves, a disponibilidade desse recurso aumenta o leque de possibilidades de recursos alimentares, e, do ponto de vista da figueira, pode aumentar a diversidade de locais de estabelecimento de seus indivíduos. Ainda assim, figos grandes de diferentes espécies de Ficus podem diferir no teor de fibras e dureza, restringindo seu consumo a animais de grande porte ou com características (dentes, garras ou bicos resistentes) que permitam o consumo desses figos, como observado em F. crocata e F. insipida.

Se esse aumento da diversidade de consumidores também fosse acompanhado de acréscimo no serviço de dispersão das sementes, o resultado dessa interação seria bastante positivo para os dois lados. Porém, mesmo sendo capazes de consumir figos maiores que a abertura de seus bicos e ingerindo suas sementes, o tamanho das aves pequenas limitou a fração de sementes potencialmente dispersas (independentemente da relação de parentesco entre as espécies de aves), representando talvez um gasto para a planta. Mas devemos considerar que a contribuição quantitativa dessas aves de pequeno porte no processo de dispersão de figos médios e grandes não deve ser comparável a aves maiores, como foi o caso de Ficus citrifolia, consumida predominantemente por ranfastídeos e cracídeos, e, principalmente, em relação aos mamíferos, que em muitos casos devem ter superado as aves no número de propágulos removidos.

A grande variação da frugivoria observada em Ficus eximia ilustra situações extremas que podem ocorrer com essas figueiras: desde uma espécie de ave com remoção de pouco figos até uma das assembléias mais diversas, com intensa taxa de frugivoria. A grande diversidade de aves observadas especificamente no indivíduo de $F$. eximia da sede da EEC pode ser consequência da atração exercida pela plantação de árvores frutíferas nas proximidades (Saracco et al. 2005) ou da escassez de recursos alimentares na área, que fez com que muitas aves passassem a incluir figos como recurso complementar em suas dietas (Terborgh 1986). Não existem dados a respeito do padrão fenológico da frutificação das comunidades vegetais das áreas de estudo, e 
trabalhos que relatam a fenologia de outras áreas de Floresta Estacional Semidecidual são divergentes no perfil encontrado, com picos de produção na estação seca (Mikich \& Silva 2001), chuvosa (Morellato 1991), ou ainda na transição da estação seca para a úmida (Morellato et al. 1989).

Independentemente do fator que levou a essa diferença, tal concentração pontual da frugivoria indica que, apesar de não atrair constantemente uma assembléia numerosa, essa figueira pode ser intensamente consumida pelas aves, sem restrição de espécies. Essa associação, no entanto, é eventual. E, assim como as demais espécies de figos verdes, mesmo sendo consumidas predominantemente por mamíferos, provavelmente é item alimentar constante na dieta de poucas aves generalistas e abundantes, como Thraupis sayaca.

Conforme esperado, as consequências da fragmentação da cobertura florestal, incluindo a perda de hábitat e o isolamento da área, sobre a comunidade de aves frugívoras foram a diminuição do número de espécies e a alteração da sua composição na área mais alterada (Gimenes \& Anjos 2003, Uezu et al. 2005). Houve o desaparecimento seletivo das espécies de grande porte, que são vulneráveis principalmente à diminuição da área total do remanescente (Martensen et al. 2008) por necessitarem de grandes áreas de forrageamento para a manutenção das populações a longo prazo (Loiselle \& Blake 1992).

Considerando, então, que Ficus eximia não é item frequente na dieta de muitas aves, apesar de ser comum e fornecer safras com grandes quantidades de figos (em comparação com F. citrifolia, por exemplo), não é surpreendente que não tenhamos detectado variações em função da fragmentação das áreas, exceto quando incluído o indivíduo da sede da EEC. Podemos concluir, então, que F. eximia, por não manter relação constante e forte com a avifauna, não sofreu alterações na sua frugivoria e tampouco na dispersão de suas sementes como conseqüência da diminuição de espécies de aves na área mais fragmentada. O mesmo deve ser esperado para as demais espécies de Ficus (F. insipida, F. crocata e F. obtusifolia), caso também não apresentem estreita relação com as aves.

Ficus citrifolia, por outro lado, apesar de não ter apresentado uma das assembléias mais diversas ou taxas de frugivoria dentre as figueiras estudadas, que pode ser uma restrição imposta pelo tamanho da árvore, teve o consumo de figos e a dispersão de sementes pelas aves diminuída pela fragmentação florestal, conforme esperado. A diferença observada, ainda, ilustra bem o efeito principal da perda de habitat sobre a avifauna - a extinção ou diminuição das populações de aves frugívoras de grande porte. 
Em alguns locais, a ausência do principal consumidor em áreas alteradas é compensada por outras espécies generalistas (p. ex. Walker et al. 1999, Moore \& Swihart 2007), proporcionando uma resiliência funcional ao sistema e atenuando o efeito da fragmentação sobre a população da espécie vegetal considerada. Neste caso, a única ave frugívora de sua assembléia no menor fragmento, Thraupis sayaca, não compensou a perda das aves de grande porte que consumiram Ficus citrifolia nas áreas menos fragmentadas.

Thraupis sayaca, ave de pequeno porte e generalista, tanto em relação à ocupação de habitat quanto à alimentação (Pizo 2004) resiste bem à perturbação e à perda de florestas (Hasui \& Höfling 1998). Assim, mesmo que a dispersão de sementes seja diminuída pela fragmentação, o fato de consumidores tolerantes à fragmentação ainda interagirem com as plantas zoocóricas nessas condições assegura, em algum nível, o deslocamento de suas sementes entre remanescentes florestais ou até mesmo na matriz antrópica, favorecendo o fluxo gênico das espécies vegetais na paisagem.

Ficus citrifolia aparentemente é favorecida pelo surgimento de bordas com a fragmentação das florestas, pois sua densidade é maior nas bordas dos fragmentos (L.F.Coelho, dados não publicados). Mais uma vez, a morfologia de seus figos, juntamente com observações de frugivoria por morcegos e a evidência de alta taxa de recrutamento em diversos locais, levam à inferência de que esses mamíferos contribuem mais para o processo de dispersão de sementes dessa figueira que as aves, e também que provavelmente estão sendo capazes de manter populações numerosas de F. citrifolia nos fragmentos e na matriz circundante.

Apenas dois indivíduos reprodutivos e um jovem de Ficus luschnathiana foram registrados no menor fragmento, onde essa espécie teve menor abundância relativa. A baixa densidade de F. luschnathiana na EERP, em contraste com os fragmentos maiores, pode ser apenas uma restrição por fatores abióticos, como a umidade do solo. Mas, visto que essa espécie seria uma das únicas do gênero Ficus na Floresta Estacional Semidecidual a manter uma relação mais forte e estreita com as aves, essa baixa densidade pode ser o reflexo da diminuição das aves frugívoras nesse fragmento ao longo das últimas décadas. Caso F. luschnathiana dependa mais da comunidade de aves que da de mamíferos para dispersar suas sementes, talvez neste caso o efeito da diminuição das aves frugívoras na área mais fragmentada seja maior que o encontrado para F. citrifolia, tanto na diminuição da interação quanto nas consequências para a população dessa figueira. 


\section{Considerações finais}

O presente estudo foi a primeira avaliação dos efeitos da perda e fragmentação de hábitat sobre a comunidade de aves frugívoras em figueiras. Dados sobre os efeitos da fragmentação florestal são desejados na Ecologia, principalmente em regiões com grande pressão antrópica. Dessa forma, a Floresta Estacional Semidecidual no Estado de São Paulo consiste em um modelo adequado de estudo, por possuir remanescentes situados em paisagens com grande amplitude no nível de fragmentação, como por exemplo as regiões do pontal do Paranapanema e de Ribeirão Preto.

A fragmentação de hábitat, apesar de sua importância ecológica, não é um fenômeno fácil de ser estudado. O maior problema metodológico é aplicar as ferramentas tradicionais de análises numéricas aos dados gerados, devido à dificuldade de padronização das unidades amostrais (por ex.: tamanho, forma e nível de conservação dos fragmentos florestais) e obtenção de amostras independentes (muitas variáveis são correlacionadas entre si e os remanescentes florestais são comumente autocorrelacionados geograficamente). Como consequência, estudos como o nosso são frequentemente criticados pelo pequeno número de amostras. No presente estudo, explicitamos que o "tamanho amostral” em nível de paisagem é 1! Qual a implicação científica desse fato? A resposta depende do rigor adotado em cada área de estudo e do quanto o pesquisador irá generalizar seus resultados. Temos consciência que os estudos sobre fragmentação e ecologia de paisagens sempre esbarrarão nessa limitação metodológica. Precisamos aprender a lidar com essa restrição e desenvolver métodos mais adequados para a análise de tais dados. Afinal, é mais desejável um estudo limitado que estudo nenhum.

Dentro desse panorama, nossos resultados indicaram que os efeitos da fragmentação florestal é complexo e variado sobre a comunidade de aves frugívoras que se alimentam em figueiras - a resposta depende de cada espécie em questão. Sabemos agora que em uma paisagem muito fragmentada a contribuição das aves na dispersão de sementes de Ficus é muito pequena, devido à perda de aves frugívoras de grande porte. Encontramos, ainda, como já relatado na literatura, que as espécies de figueiras podem ser classificadas em duas guildas, de acordo com o grupo de dispersores: aves e mamíferos. Assim, espécies de Ficus com características morfológicas associadas à dispersão por aves (por ex.: figos vermelhos e pequenos), provavelmente sofrem maior efeito negativo com a exclusão das aves frugívoras de grande porte. 
Os resultados apresentados abrem novas oportunidades de estudo, os quais contribuirão para o melhor entendimento dos efeitos da perda e fragmentação de hábitat. Tais como: 1) O efeito da fragmentação é igual em figueiras dispersas por aves ou mamíferos? 2) As estruturas das comunidades de frugívoros e de figueiras são alteradas em sentidos semelhantes ou diferentes com a fragmentação? 3) Quais os efeitos de microhábitat sobre a comunidade frugívora? 4) Os efeitos da fragmentação sobre a comunidade frugívora de Ficus são reversíveis com a restauração do hábitat? Essas são umas das questões que vieram em mente durante o desenvolvimento do estudo. Esperamos que algumas delas desperte o interesse e o entusiasmo de novos pesquisadores nessa área. 


\section{Referências bibliográficas}

Anjos, L. dos. 2006. Bird species sensitivity in a fragmented landscape of the Atlantic Forest in southern Brazil. Biotropica 38: 229-234.

Argel-de-Oliveira, M.M., \& Figueiredo, R.A. 1996. Aves que visitam uma figueira isolada em ambiente aberto, Espírito Santo, Brasil. Iheringia, Série Zoológica 80:127-134.

Berg, C.C., \& Villavicencio, X. 2004. Taxonomic studies on Ficus (Moraceae) in the West Indies, extra-Amazonian Brazil and Bolivia. Ilicifolia 4:1-173.

Betini, G.S. 2001. Amostragem de aves por pontos numa floresta estacional semidecidual. Dissertação de Mestrado. Universidade de São Paulo, Piracicaba, SP.

Bleher, B., Potgieter, C.J., Johnson, D.N., \& Böhning-Gaese, K. 2003. The importance of figs for frugivores in a South African coastal forest. Journal of Tropical Ecology 19:375-386.

Canty, A., \& Ripley, B. 2009. boot: Bootstrap R (S-Plus) Functions. R package version 1.2-37.

CBRO (Comitê Brasileiro de Registros Ornitológicos). Lista das aves do Brasil, versão16/08/2007. Disponível em: <http://www.cbro.org.br>. Acesso em: 06 de setembro de 2007.

Compton, S.G., Wiebes, T., \& Berg, C.C. 1996. The Biology of Fig Trees and Their Associated Animals. Journal of Biogeography 23:405-407.

Cordeiro, N.J., \& Howe, H.F. 2003. Forest fragmentation severs mutualism between seed dispersers and an endemic African tree. Proceedings of the National Academy of Sciences of the United States 100:14052-14056.

Crawley, M.J. 2005. Statistics: an Introduction Using R. John Wiley \& Sons, Ltd, Chichester.

Dormann, C.F., Gruber B., \& Fründ, J. 2008. Introducing the bipartite Package: Analysing Ecological Networks. R news Vol 8/2, 8 - 11.

Durigan, G., Franco, G.A.D.C., Saito, M., \& Baitello, J.B. 2000. Estrutura e diversidade do componente arbóreo da floresta na Estação Ecológica dos Caetetus, Gália, SP. Revista Brasileira de Botânica 23:371-383.

Ellison, A.M. 1993. Exploratory data analysis and graphic display In: Scheiner, S. M. (ed.), Design and analysis of ecological experiments. Chapman \& Hall, New York. pp. 14-45.

Fadini, R.F., \& Marco Jr., P.D. 2004. Interações entre aves frugívoras e plantas em um fragmento de mata atlântica de Minas Gerais. Ararajuba 12:97-103.

Fahrig, L. 2003. Effects of Habitat Fragmentation on biodiversity. Annual Reviews of Ecological and Evolutionary Systems 34:487-515.

Faria, H.H. 2006. Parque Estadual do Morro do Diabo: plano de manejo. Editora Viena, Santa Cruz do Rio Pardo, SP.

Farwig. N., Böhning-Gaese, K., \& Bleher, B. 2006. Enhanced seed dispersal of Prunus africana in fragmented and disturbed forests? Oecologia 147:238-252.

Galetti, M., \& Pizo, M.A. 1996. Fruit eating by birds in a forest fragment in southeastern Brazil. Ararajuba 4:71-79. 
Galetti, M., Alves-Costa, C.P., \& Cazetta, E. 2003a. Effects of forest fragmentation, anthropogenic edges and fruit colour on the consumption of ornithocoric fruits. Biological Conservation 111:269-273.

Galetti, M., Pizo, M.A., \& Morellato, L.P.C. 2003b. Métodos para o estudo da fenologia, frugivoria e dispersão de sementes. In: Laury Cullen Jr., C.V. Padua, R.Rudran. (Org.). Métodos de Estudos em Biologia da Conservação e Manejo da Vida Silvestre. Editora UFPR, Curitiba. pp. 395-422.

Gimenes, M.R., \& Anjos, L. 2003. Efeitos da fragmentação florestal sobre as comunidades de aves. Acta Scientiarum. Biological Sciences 25: 391-402.

Groom, M.J., Meffe, G.K., \& Carroll, C.R. 2006. Principles of Conservation Biology. Sinauer Associates, Massachusetts, USA.

Hamrick, J.L., \& Godt, M.J.W. 1996. Effects of Life History Traits on Genetic Diversity in Plant Species. Philosophical Transactions: Biological Sciences 1345:1291-1298.

Hasui, E., \& Höfling, E. 1998. Preferência alimentar das aves frugívoras em um fragmento de floresta estacional semidecídua secundária, São Paulo, Brasil. Iheringia, Série Zoológica 84:43-64.

Howe, H.F., \& Smallwood, J. 1982. Ecology of seed dispersal. Annual Review of Ecology and Systematics 13:201-228.

Janzen, D.H. 1979. How to be a fig. Annual Review of Ecology and Systematics 10:1351.

Jordano, P., Galetti, M., Pizo, M.A., \& Silva, W.R. 2006. Ligando Frugivoria e Dispersão de Sementes à Biologia da Conservação. In: C.F. Duarte, H.G. Bergallo, M.A. dos Santos, A.E. Va. (eds.). Biologia da conservação: essências. Editora Rima, São Paulo. pp. 411-436.

Kalko, E.K.V., Herre, E.A., \& Handley, C.O. 1996. Relation of fig fruit characteristis to fruit-eating bats in the New and Old World tropics. Journal of Biogeography 23:565576.

Kinnaird, M.F., O'Brien, T.G., \& Suryadi, S. 1996. Population fluctuation in Sulawesi Red-knobbed Hornbills: tracking figs in space and time. The Auk 113:431-440.

Kirika, J.M., Bleher, B., Böhning-Gaese, K., Chira, R., \& Farwig, N. 2008 Fragmentation and local disturbance of forests reduce frugivore diversity and fruit removal in Ficus thonningii. Basic Applied Ecology 9:663-672.

Korine, C., Kalko, E.K.V., \& Herre, E.A. 2000. Fruit characteristics and factor affecting fruit removal in a Panamanian community of strangler figs. Oecologia 123:560-568.

Kotchetkoff-Henriques, O. 2003. Caracterização da vegetação natural em Ribeirão Preto, SP: bases para conservação. Tese de Doutorado. Universidade de São Paulo, Ribeirão Preto,SP.

Lambert, F.R., \& Marshall, A.G. 1991. Keystone characteristics of bird-dispersed Ficus in a Malaysian lowland rain forest. Journal of Ecology 79:793-809.

Loiselle, B.A., \& Blake, J.G. 1992. Population variation in a tropical bird community: Implications for conservation. BioScience 42:838-845.

Manhães, M.A. 2003. Dieta de Traupíneos (Passeriformes, Emberizidae) no Parque Estadual do Ibitipoca, Minas Gerais, Brasil. Iheringia, Série Zoologia 93:59-73. 
Manly, B.F.J. 1997. Randomization, Bootstrap and Monte Carlo Methods in Biology. 2a. edição. Chapman \& Hall London.

Martensen, A.C., Pimentel, R.G.,\& Metzger, J.P., 2008. Relative effects of fragment size and connectivity on bird community in the Atlantic Rain Forest: implications for conservation. Biological Conservation 141:2184-2192.

McKey, D. 1989. Population biology of figs: Applications for conservation. Experientia 45:661-673.

Midya, S., \& Brahmachary, R.L. 1991. The effect of birds upon germination of banyan (Ficus bengalensis) seeds. Journal of Tropical Ecology 7:537-538.

Mikich, S. B. 2002. A dieta frugívora de Penelope superciliaris (Cracidae) em remanescentes de floresta estacional semidecidual no centro-oeste do Paraná, Brasil, e sua relação com Euterpe edulis (Arecaceae). Ararajuba 10: 207-217.

Mikich, S. B., Silva, S. M. 2001. Composição florística e fenologia das espécies zoocóricas de remanescentes de floresta estacional semidecidual no centro-oeste do Paraná, Brasil. Acta Botânica Brasílica, v.15, n.1, p.89-113.

Mikich, S.B. 2002. A dieta frugívora de Penelope superciliaris (Cracidae) em remanescnetes de Floresta Estacional Semidecidual no centro-oeste do Paraná e sua relação com Euterpe edulis (Arecaceae). Ararajuba 10:207-217.

Moore, J.E., \& Swihart, R.K. 2007. Importance of fragmentation-tolerant species as seed dispersers in disturbed landscapes. Oecologia 151:663-674.

Morellato L. P. C. 1991. Estudo da fenologia de árvores, arbustos e lianas de uma floresta semidecidua no sudeste do Brasil. Tese de Doutorado. Universidade Estadual de Campinas, Campinas.

Morellato, L. P. C., Rodrigues, R. R., Leitão Filho, H. F., \& Joly, C. A. 1989. Estudo comparativo da fenologia de espécies arbóreas de floresta de altitude e floresta semidecídua semidecídua na Serra do Japi, Jundiai, São Paulo. Revista brasileira de Botânica 12: 85-98.

Murcia, C. 1995. Edge effects in fragmented forests: implications for conservation. Tree 10:58-62.

O'Brien, T.G., Kinnaird, M.F., \& Dierenfeld, E.S. 1998. What's so special about figs? Nature 392:668.

Pascotto, M.C. 2006. Avifauna dispersora de sementes de Alchornea glandulosa (Euphorbiaceae) em uma área de mata ciliar no estado de São Paulo. Revista Brasileira de Ornitologia 14:291-296.

Patterson, B.D. 1987. The Principle of Nested Subsets and Its Implications for Biological Conservation. Conservation Biology 1: 323-334.

Peh, K.S.H., \& Chong, F.L. 2003. Seed dispersal agents of two Ficus species in a disturbed tropical forest. Ornithological Science 2:119-125.

Peres, C.A. 2000. Identifying keystone plant resources in tropical forests: the case of gums from Parkia pods. Journal of Tropical Ecology 16:287-317.

Piratelli, A., M.R., \& Pereira 2002. Dieta de aves na região leste de Mato Grosso do Sul, Brasil. Ararajuba. 10: 131-139.

Pizo, M.A. 2004. Frugivory and habitat use by fruit-eating birds in a fragmented landscape of southeast Brazil. Ornitologia Neotropical 15:117-126. 
Pratt, TK, \& Stiles, E.W. 1985. The influence of fruit size and structure on composition of frugivore assemblages in New Guinea. Biotropica 17: 314-321.

Putz, F. E., \& Holbrook, N. M. 1989. Strangler fig rooting habitats and nutrient relations in the llanos of Venezuela. American Journal of Botany. 76:781-788.

Ragusa-Netto, J. 2002. Fruiting phenology and consumption by birds in Ficus calyptroceras (Miq.) Miq. (Moraceae). Brazilian Journal of Biology 62:339-346.

Restrepo, C., \& Gomez, N. 1998. Responses of Understory Birds to Anthropogenic Edges in a Neotropical Montane Forest. Ecological applications 8:170-183.

Restrepo, C., Gomez, N., \& Heredia, S. 1999. Anthropogenic Edges, Treefall Gaps, and Fruit-Frugivore Interactions in a Neotropical Montane Forest. Ecology 80:668-685.

Rosa, G.A.B. 2004. Frugivoria e dispersão de sementes por aves em uma área de reflorestamento misto em Botucatu, SP. Dissertação de Mestrado. Universidade Estadual de Campinas, Campinas, SP.

Saracco, J., Collazzo, J.A., Groom, M.J., \& Carlo, A.T. 2005. Crop size and fruit neighborhood effects on bird visitation to fruiting Schefflera morototoni trees in Puerto Rico. Biotropica 37: 81-87.

Schemske, D.W., \& Brokaw, N. 1981. Treefalls and the Distribution of Understory Birds in a Tropical Forest. Ecology 62:938-945.

Schupp, E. W., Milleron, T., \& Russo, S. 2002. Dissemination limitation and the origin and maintenance of species-rich tropical forests. In Levey, D. J., W. R. Silva \& M. Galetti (eds.). Seed dispersal and frugivory: ecology, evolution and conservation. . CAB International, Wallingford, UK. pp. 19-33.

Shanahan, M., So, S., Compton, S.G., \& Corlett, R. 2001. Fig-eating by vertebrate frugivores: a global review. Biological Reviews 76:529-572.

Sick, H. 1997. Ornitologia Brasileira. Nova fronteira, Rio de Janeiro.

Sigrist, T. 2005. Aves do Brasil: uma visão artística. Avis Brasilis, São Paulo.

Sigrist, T. 2007. Aves do Brasil oriental. Avis Brasilis, São Paulo.

Snow, D.W. 1981. Tropical frugivorous birds and their food plants: a world survey. Biotropica 13:1-14.

Souza, D.G.S. 1998. Todas as aves do Brasil: guia de campo para identificação. Editora Dall, Bahia.

Stotz, D. F., Fitzpatrick, J. W., Parker III, T. A., \& Moskovits, D. B. 1996. Neotropical birds: ecology and conservation. University of Chicago Press, Chicago.

Tabanez, M.F., Durigan, G., Keuroghlian, A.F., Barbosa, A.F., Freitas, C.A., Silva, C.E.F., Silva, D.A., Eaton, D.P., Brisolla, G., Faria, H.H., Mattos, I.F.A., Lobo, M.T., Barbosa, M.R., Rossi, M., Souza, M.G., Machado, R.B., Pfeifer, R.M., Ramos, V.S., Andrade, W.J., \& Contieri, W.A. 2005. Plano de Manejo da Estação Ecológica dos Caetetus. Instituto Florestal, São Paulo, SP.

Terborgh, J. 1986. Keystone plant resources in the Tropical forest. In: Soulé, M.E. (ed.), Conservation Biology. Sinauer Associates, Sunderland, Massachusetts, USA. pp. 330-344.

Uezu, A., Metzger, J.P., \& Vielliard, J.M.E. 2005. Effects of structural and functional connectivity and patch size on the abundan of seven Atlantic Forest bird species. Biological Conservation 123:507-519. 
Walker, B., Kinzig, A., \& Langridge, J. 1999. Plant attribute diversity, resilience, and ecosystem function: the nature and significance of dominant and minor species. Ecosystems 2:95-113.

Wheelwright, N.T. 1993. Fruit size in a tropical tree species: variation, preference by birds, and heritability. Vegetatio 107/108:163-174.

Willis, E.O. 1979. The composition of avian communities in remanescent woodlots in southern Brazil. Papéis Avulsos de Zoologia 33:1-25.

Willis, E.O., \& Oniki, Y. 1981. Levantamento preliminar de aves em treze áreas do Estado de São Paulo. Revista Brasileira de Biologia 41: 121-135.

Willson, M. \& Traveset, A. 1900. The Ecology of Seed Dispersal In: M. Fenner (ed.) Seeds: The ecology of regeneration in plant communities. 2a. edição. CAB International, Wallingford, UK. pp. 85-110.

Wright, S. J., Zeballos, H., Dominguez, I., Gallardo, M. M., Moreno M. C., \& Ibañez, R. 2000. Poachers alter mammal abundance, seed dispersal, and seed predation in a neotropical forest. Conservation Biology 14: 227-239. 
Anexos 
Anexo 1. Aves frugívoras que ocorrem em cada fragmento florestal estudado. PEMD = Parque Estadual do Morro do Diabo, EEC = Estação Ecológica dos Caetetus, EERP = Estação Ecológica de Ribeirão Preto. (X) Ocorrência registrada (Willis \& Oniki 1981, Betini 2001, Tabanez et al. 2005, Faria 2006, M.E. Lapate, obs. pessoal). (-) Fora da área de ocorrência biogeográfica (Sigrist 2007).

\begin{tabular}{|c|c|c|c|c|}
\hline Família & Espécie & PEMD & EEC & EERP \\
\hline \multirow{7}{*}{ Tinamidae } & Tinamus solitarius & $\mathrm{X}$ & & \\
\hline & Crypturellus obsoletus & $\mathrm{X}$ & $\mathrm{X}$ & \\
\hline & Crypturellus undulatus & $\mathrm{X}$ & & \\
\hline & Crypturellus parvirostris & $\mathrm{X}$ & $\mathrm{X}$ & $\mathrm{X}$ \\
\hline & Crypturellus tataupa & $\mathrm{X}$ & $\mathrm{X}$ & \\
\hline & Rhynchotus rufescens & $\mathrm{X}$ & $\mathrm{X}$ & \\
\hline & Nothura maculosa & $\mathrm{X}$ & $\mathrm{X}$ & \\
\hline Cracidae & Penelope superciliaris & $\mathrm{X}$ & $\mathrm{X}$ & $\mathrm{X}$ \\
\hline Odontophoridae & Odontophorus capueira & $\mathrm{X}$ & $\mathrm{X}$ & \\
\hline \multirow[t]{11}{*}{ Columbidae } & Columbina minuta & $\mathrm{X}$ & - & \\
\hline & Columbina talpacoti & $\mathrm{X}$ & $\mathrm{X}$ & $\mathrm{X}$ \\
\hline & Columbina squammata & $\mathrm{X}$ & $\mathrm{X}$ & $\mathrm{X}$ \\
\hline & Claravis pretiosa & $\mathrm{X}$ & $\mathrm{X}$ & \\
\hline & Patagioenas picazuro & $\mathrm{X}$ & $\mathrm{X}$ & $\mathrm{X}$ \\
\hline & Patagioenas cayennensis & $\mathrm{X}$ & & $\mathrm{X}$ \\
\hline & Zenaida auriculata & $\mathrm{X}$ & $\mathrm{X}$ & $\mathrm{X}$ \\
\hline & Leptotila verreauxi & $\mathrm{X}$ & $\mathrm{X}$ & $\mathrm{X}$ \\
\hline & Leptotila rufaxilla & $\mathrm{X}$ & $\mathrm{X}$ & \\
\hline & Geotrygon violacea & $\mathrm{X}$ & $\mathrm{X}$ & \\
\hline & Geotrygon montana & & $\mathrm{X}$ & \\
\hline \multirow[t]{11}{*}{ Psittacidae } & Ara ararauna & $\mathrm{X}$ & & \\
\hline & Ara chloropterus & $\mathrm{X}$ & - & - \\
\hline & Primolius maracana & & $\mathrm{X}$ & \\
\hline & Aratinga leucophthalma & $\mathrm{X}$ & $\mathrm{X}$ & $\mathrm{X}$ \\
\hline & Aratinga auricapillus & & & $\mathrm{X}$ \\
\hline & Aratinga aurea & & & $\mathrm{X}$ \\
\hline & Pyrrhura frontalis & $\mathrm{X}$ & $\mathrm{X}$ & - \\
\hline & Forpus xanthopterygius & $\mathrm{X}$ & $\mathrm{X}$ & $\mathrm{X}$ \\
\hline & Brotogeris chiriri & $\mathrm{X}$ & $X$ & $X$ \\
\hline & Pionus maximiliani & $\mathrm{X}$ & $\mathrm{X}$ & \\
\hline & Amazona aestiva & $\mathrm{X}$ & & $\mathrm{X}$ \\
\hline \multirow[t]{2}{*}{ Cuculidae } & Crotophaga ani & $\mathrm{X}$ & $\mathrm{X}$ & $\mathrm{X}$ \\
\hline & Guira guira & $\mathrm{X}$ & $\mathrm{X}$ & $\mathrm{X}$ \\
\hline \multirow[t]{2}{*}{ Trogonidae } & Trogon surrucura & $\mathrm{X}$ & $\mathrm{X}$ & \\
\hline & Trogon rufus & $\mathrm{X}$ & $\mathrm{X}$ & \\
\hline \multirow[t]{2}{*}{ Momotidae } & Baryphthengus ruficapillus & $\mathrm{X}$ & $\mathrm{X}$ & \\
\hline & Momotus momota & $\mathrm{X}$ & - & - \\
\hline \multirow[t]{6}{*}{ Ramphastidae } & Ramphastos toco & $\mathrm{X}$ & $\mathrm{X}$ & $\mathrm{X}$ \\
\hline & Ramphastos dicolorus & $\mathrm{X}$ & $\mathrm{X}$ & \\
\hline & Selenidera maculirostris & $\mathrm{X}$ & & - \\
\hline & Pteroglossus bailloni & - & $\mathrm{X}$ & - \\
\hline & Pteroglossus aracari & $\mathrm{X}$ & $X$ & \\
\hline & Pteroglossus castanotis & $\mathrm{X}$ & $\mathrm{X}$ & - \\
\hline Picidae & Melanerpes candidus & $\mathrm{X}$ & $\mathrm{X}$ & $\mathrm{X}$ \\
\hline
\end{tabular}


Anexo 1. (Continuação)

\begin{tabular}{|c|c|c|c|c|}
\hline Família & Espécie & PEMD & EEC & EERP \\
\hline \multirow{30}{*}{ Tyrannidae } & Melanerpes flavifrons & $\mathrm{X}$ & $\mathrm{X}$ & \\
\hline & Veniliornis passerinus & $\mathrm{X}$ & $\mathrm{X}$ & $\mathrm{X}$ \\
\hline & Veniliornis spilogaster & $X$ & $X$ & \\
\hline & Colaptes melanochloros & $\mathrm{X}$ & $X$ & $\mathrm{X}$ \\
\hline & Colaptes campestris & $\mathrm{X}$ & $\mathrm{X}$ & $\mathrm{X}$ \\
\hline & Celeus flavescens & $\mathrm{X}$ & $\mathrm{X}$ & \\
\hline & Dryocopus lineatus & $\mathrm{X}$ & $\mathrm{X}$ & $\mathrm{X}$ \\
\hline & Campephilus robustus & $X$ & $\mathrm{X}$ & $X$ \\
\hline & Elaenia flavogaster & $\mathrm{X}$ & $\mathrm{X}$ & $\mathrm{X}$ \\
\hline & Elaenia albiceps & & $\mathrm{X}$ & \\
\hline & Elaenia chiriquensis & $\mathrm{X}$ & & \\
\hline & Camptostoma obsoletum & $\mathrm{X}$ & $\mathrm{X}$ & \\
\hline & Serpophaga subcristata & & $\mathrm{X}$ & \\
\hline & Knipolegus cyanirostris & $\mathrm{X}$ & $X$ & \\
\hline & Satrapa icterophrys & $\mathrm{X}$ & $\mathrm{X}$ & \\
\hline & Xolmis velatus & $\mathrm{X}$ & $\mathrm{X}$ & \\
\hline & Legatus leucophaius & $X$ & & $\mathrm{X}$ \\
\hline & Myiozetetes similis & $X$ & $X$ & $\mathrm{X}$ \\
\hline & Pitangus sulphuratus & $\mathrm{X}$ & $\mathrm{X}$ & $\mathrm{X}$ \\
\hline & Myiodynastes maculatus & $\mathrm{X}$ & $\mathrm{X}$ & $\mathrm{X}$ \\
\hline & Megarynchus pitangua & $\mathrm{X}$ & $\mathrm{X}$ & $\mathrm{X}$ \\
\hline & Empidonomus varius & & $\mathrm{X}$ & $\mathrm{X}$ \\
\hline & Griseotyrannus aurantioatrocristatus & & & $\mathrm{X}$ \\
\hline & Tyrannus melancholicus & $\mathrm{X}$ & $\mathrm{X}$ & $\mathrm{X}$ \\
\hline & Tyrannus tyrannus & - & $\mathrm{X}$ & - \\
\hline & Tyrannus savana & $\mathrm{X}$ & $\mathrm{X}$ & $\mathrm{X}$ \\
\hline & Myiarchus swainsoni & $\mathrm{X}$ & $\mathrm{X}$ & \\
\hline & Myiarchus ferox & $\mathrm{X}$ & $\mathrm{X}$ & $\mathrm{X}$ \\
\hline & Myiarchus tyrannulus & $\mathrm{X}$ & $\mathrm{X}$ & $\mathrm{X}$ \\
\hline & Attila rufus & - & $\mathrm{X}$ & - \\
\hline \multirow[t]{2}{*}{ Cotingidae } & Procnias nudicollis & $\mathrm{X}$ & $\mathrm{X}$ & \\
\hline & Pyroderus scutatus & $\mathrm{X}$ & & \\
\hline \multirow[t]{6}{*}{ Pipridae } & Tyranneutes virescens & $\mathrm{X}$ & - & - \\
\hline & Piprites chloris & $\mathrm{X}$ & - & - \\
\hline & Manacus manacus & $\mathrm{X}$ & & \\
\hline & Antilophia galeata & $\mathrm{X}$ & $\mathrm{X}$ & $\mathrm{X}$ \\
\hline & Chiroxiphia caudata & $X$ & $X$ & \\
\hline & Pipra fasciicauda & $\mathrm{X}$ & & \\
\hline \multirow[t]{7}{*}{ Tityridae } & Schiffornis virescens & & $\mathrm{X}$ & \\
\hline & Laniisoma elegans & $\mathrm{X}$ & $X$ & - \\
\hline & Tityra inquisitor & $\mathrm{X}$ & & \\
\hline & Tityra cayana & $\mathrm{X}$ & $\mathrm{X}$ & \\
\hline & Pachyramphus viridis & $\mathrm{X}$ & $\mathrm{X}$ & \\
\hline & Pachyramphus polychopterus & $\mathrm{X}$ & $X$ & \\
\hline & Pachyramphus validus & & $X$ & \\
\hline \multirow[t]{3}{*}{ Vireonidae } & Cyclarhis gujanensis & $\mathrm{X}$ & $\mathrm{X}$ & $\mathrm{X}$ \\
\hline & Vireo olivaceus & $\mathrm{X}$ & $\mathrm{X}$ & $\mathrm{X}$ \\
\hline & Hylophilus poicilotis & $\mathrm{X}$ & $\mathrm{X}$ & $\mathrm{X}$ \\
\hline
\end{tabular}


Anexo 1. (Continuação)

\begin{tabular}{|c|c|c|c|c|}
\hline Família & Espécie & PEMD & EEC & EERP \\
\hline \multirow[t]{2}{*}{ Corvidae } & Cyanocorax cristatellus & & $\mathrm{X}$ & \\
\hline & Cyanocorax chrysops & $\mathrm{X}$ & $\mathrm{X}$ & $\mathrm{X}$ \\
\hline \multirow{5}{*}{ Turdidae } & Turdus rufiventris & $\mathrm{X}$ & $\mathrm{X}$ & \\
\hline & Turdus leucomelas & $\mathrm{X}$ & $\mathrm{X}$ & $\mathrm{X}$ \\
\hline & Turdus amaurochalinus & $\mathrm{X}$ & $\mathrm{X}$ & $\mathrm{X}$ \\
\hline & Turdus subalaris & $\mathrm{X}$ & $\mathrm{X}$ & \\
\hline & Turdus albicollis & $\mathrm{X}$ & $\mathrm{X}$ & \\
\hline Mimidae & Mimus saturninus & $\mathrm{X}$ & $\mathrm{X}$ & $\mathrm{X}$ \\
\hline Coerebidae & Coereba flaveola & $\mathrm{X}$ & $\mathrm{X}$ & $\mathrm{X}$ \\
\hline \multirow[t]{17}{*}{ Thraupidae } & Cissopis leverianus & $\mathrm{X}$ & $\mathrm{X}$ & \\
\hline & Neothraupis fasciata & $\mathrm{X}$ & & \\
\hline & Nemosia pileata & $\mathrm{X}$ & $\mathrm{X}$ & $\mathrm{X}$ \\
\hline & Thlypopsis sordida & & $\mathrm{X}$ & $\mathrm{X}$ \\
\hline & Trichothraupis melanops & $\mathrm{X}$ & $\mathrm{X}$ & \\
\hline & Habia rubica & $\mathrm{X}$ & $\mathrm{X}$ & - \\
\hline & Tachyphonus coronatus & $\mathrm{X}$ & $\mathrm{X}$ & \\
\hline & Tachyphonus rufus & & $\mathrm{X}$ & - \\
\hline & Ramphocelus carbo & $\mathrm{X}$ & $\mathrm{X}$ & \\
\hline & Thraupis sayaca & $\mathrm{X}$ & $\mathrm{X}$ & $\mathrm{X}$ \\
\hline & Pipraeidea melanonota & $\mathrm{X}$ & $\mathrm{X}$ & - \\
\hline & Tangara cayana & $\mathrm{X}$ & $X$ & $\mathrm{X}$ \\
\hline & Tersina viridis & $\mathrm{X}$ & $\mathrm{X}$ & $\mathrm{X}$ \\
\hline & Dacnis cayana & $\mathrm{X}$ & $\mathrm{X}$ & $\mathrm{X}$ \\
\hline & Hemithraupis guira & $\mathrm{X}$ & $\mathrm{X}$ & $X$ \\
\hline & Hemithraupis ruficapilla & $\mathrm{X}$ & $\mathrm{X}$ & $X$ \\
\hline & Conirostrum speciosum & $\mathrm{X}$ & $\mathrm{X}$ & $\mathrm{X}$ \\
\hline \multirow[t]{5}{*}{ Emberizidae } & Zonotrichia capensis & $\mathrm{X}$ & $\mathrm{X}$ & $\mathrm{X}$ \\
\hline & Ammodramus humeralis & $\mathrm{X}$ & $\mathrm{X}$ & $\mathrm{X}$ \\
\hline & Volatinia jacarina & $\mathrm{X}$ & $\mathrm{X}$ & $\mathrm{X}$ \\
\hline & Arremon flavirostris & $\mathrm{X}$ & $\mathrm{X}$ & $\mathrm{X}$ \\
\hline & Coryphospingus cucullatus & $\mathrm{X}$ & $X$ & $X$ \\
\hline \multirow[t]{3}{*}{ Cardinalidae } & Saltator fuliginosus & - & $\mathrm{X}$ & - \\
\hline & Saltator similis & $\mathrm{X}$ & $\mathrm{X}$ & \\
\hline & Cyanoloxia glaucocaerulea & $\mathrm{X}$ & & \\
\hline \multirow[t]{8}{*}{ Icteridae } & Procacicus solitarius & & - & $\mathrm{X}$ \\
\hline & Cacicus haemorrhous & $\mathrm{X}$ & $\mathrm{X}$ & \\
\hline & Icterus cayanensis & $\mathrm{X}$ & $\mathrm{X}$ & $\mathrm{X}$ \\
\hline & Gnorimopsar chopi & $\mathrm{X}$ & $\mathrm{X}$ & $X$ \\
\hline & Amblyramphus holosericeus & $\mathrm{X}$ & & \\
\hline & Chrysomus ruficapillus & $\mathrm{X}$ & & \\
\hline & Molothrus bonariensis & $\mathrm{X}$ & & $\mathrm{X}$ \\
\hline & Sturnella militaris & $\mathrm{X}$ & - & - \\
\hline \multirow[t]{2}{*}{ Fringillidae } & Euphonia chlorotica & $\mathrm{X}$ & $\mathrm{X}$ & $\mathrm{X}$ \\
\hline & Euphonia violacea & $\mathrm{X}$ & $\mathrm{X}$ & \\
\hline Passeridae & Passer domesticus & & $\mathrm{X}$ & $\mathrm{X}$ \\
\hline Total & 137 & 118 & 110 & 64 \\
\hline
\end{tabular}


Anexo 2. Taxas de frugivoria (TF) e dispersão (TD), porcentagens de figos removidos e dispersos, probabilidade de dispersão (PD) e número de figos cuja fração de consumo foi registrada (n) das aves em cada espécie de Ficus, na ordem decrescente da taxa de frugivoria. (-) Parâmetros não determinados por ausência de visitas acompanhadas na íntegra.

\begin{tabular}{lccccc}
\hline Espécie & $\begin{array}{c}\mathrm{TF} \\
\text { (figos. } \mathrm{h}^{-1} \text { ) }\end{array}$ & $\begin{array}{c}\text { \% Figos } \\
\text { removidos }\end{array}$ & $\begin{array}{c}\text { TD } \\
\text { (figos. } \mathrm{h}^{-1} \text { ) }\end{array}$ & $\begin{array}{c}\text { \% Figos } \\
\text { dispersos }\end{array}$ & PD (n) \\
$\begin{array}{l}\text { Ficus citrifolia } \\
\text { Pteroglossus castanotis }\end{array}$ & 0,63 & $43,1 \%$ & 0,50 & $48,8 \%$ & $79,4 \%$ \\
Thraupis sayaca & 0,34 & $23,5 \%$ & 0,16 & $15,8 \%$ & $47,2 \%$ \\
Penelope superciliaris & 0,28 & $19,1 \%$ & 0,26 & $25,2 \%$ & $92,3 \%$ \\
Tangara cayana & 0,08 & $5,5 \%$ & 0,05 & $4,5 \%$ & $57,1 \%$ \\
Dacnis cayana & 0,07 & $4,6 \%$ & 0,02 & $2,2 \%$ & $33,3 \%$ \\
Ramphocelus carbo & 0,05 & $3,2 \%$ & 0,02 & $2,2 \%$ & $47,6 \%$ \\
Pteroglossus aracari & 0,01 & $0,9 \%$ & 0,01 & $1,3 \%$ & $100,0 \%$ \\
Cissopis leverianus & - & - & - & - & - \\
Hemithraupis guira & - & - & - & - & - \\
Tricothraupis melanops & - & - & - & - & - \\
Habia rubica & - & - & - & - & -
\end{tabular}

$\begin{array}{lccccc}\text { Ficus crocata } & & & & \\ \text { Pyrrhura frontalis } & 25,33 & 98,4 \% & 0,00 & 0,0 \% & 0,0 \% \\ \text { Pteroglossus castanotis } & 0,31 & 1,2 \% & 0,16 & 86,5 \% & 53,3 \% \\ \text { Turdus leucomelas } & 0,06 & 0,2 \% & 0,01 & 6,8 \% & 22,2 \% \\ \text { Cissopis leverianus } & 0,04 & 0,1 \% & 0,01 & 6,8 \% & 33,3 \% \\ \text { Tityra cayana } & - & - & - & - & -\end{array}$

$\begin{array}{lccccc}\text { Ficus eximia } & & & & \\ \text { Thraupis sayaca } & 12,37 & 55,2 \% & 4,58 & 53,9 \% & 37,1 \% \\ \text { Tersina viridis } & 3,30 & 14,8 \% & 1,31 & 15,4 \% & 39,6 \% \\ \text { Brotogeris chiriri } & 1,68 & 7,5 \% & 0,00 & 0,0 \% & 0,0 \% \\ \text { Penelope superciliaris } & 1,16 & 5,2 \% & 0,97 & 11,4 \% & 83,3 \% \\ \text { Ramphocelus carbo } & 0,65 & 2,9 \% & 0,32 & 3,8 \% & 49,0 \% \\ \text { Dacnis cayana } & 0,48 & 2,2 \% & 0,10 & 1,2 \% & 21,3 \% \\ \text { Turdus amaurochalinus } & 0,47 & 2,1 \% & 0,20 & 2,3 \% & 41,7 \% \\ \text { Trogon surrucura } & 0,45 & 2,0 \% & 0,39 & 4,6 \% & 87,0 \% \\ \text { Tangara cayana } & 0,36 & 1,6 \% & 0,12 & 1,4 \% & 31,7 \% \\ \text { Turdus leucomelas } & 0,34 & 1,5 \% & 0,18 & 2,1 \% & 52,2 \% \\ \text { Pionus maximiliani } & 0,29 & 1,3 \% & 0,00 & 0,0 \% & 0,0 \% \\ \text { Ramphastos toco } & 0,15 & 0,7 \% & 0,07 & 0,8 \% & 45,2 \%\end{array}$


Anexo 2. (Continuação)

\begin{tabular}{|c|c|c|c|c|c|c|}
\hline Espécie & $\begin{array}{c}\mathrm{TF} \\
\text { (figos.h }^{-1} \text { ) }\end{array}$ & $\begin{array}{c}\text { \% Figos } \\
\text { removidos }\end{array}$ & $\begin{array}{c}\text { TD } \\
\text { (figos.h }^{-1} \text { ) }\end{array}$ & $\begin{array}{c}\text { \% Figos } \\
\text { dispersos }\end{array}$ & \multicolumn{2}{|c|}{ PD (n) } \\
\hline \multicolumn{7}{|l|}{ Ficus eximia (cont.) } \\
\hline Zonotrichia capensis & 0,14 & $0,6 \%$ & 0,03 & $0,4 \%$ & $22,2 \%$ & (9) \\
\hline Conirostrum speciosum & 0,11 & $0,5 \%$ & 0,04 & $0,4 \%$ & $33,3 \%$ & (4) \\
\hline Turdus rufiventris & 0,10 & $0,4 \%$ & 0,03 & $0,4 \%$ & $33,3 \%$ & (6) \\
\hline Pteroglossus castanotis & 0,08 & $0,4 \%$ & 0,08 & $1,0 \%$ & $100,0 \%$ & (4) \\
\hline Habia rubica & 0,06 & $0,3 \%$ & 0,03 & $0,4 \%$ & $47,6 \%$ & (7) \\
\hline Pitangus sulphuratus & 0,06 & $0,2 \%$ & 0,01 & $0,2 \%$ & $26,7 \%$ & (5) \\
\hline Forpus xanthopterygius & 0,04 & $0,2 \%$ & 0,00 & $0,0 \%$ & $0,0 \%$ & (3) \\
\hline Hemithraupis guira & 0,04 & $0,2 \%$ & 0,03 & $0,3 \%$ & $66,7 \%$ & (1) \\
\hline Chiroxiphia caudata & 0,02 & $0,1 \%$ & 0,01 & $0,1 \%$ & $44,4 \%$ & (3) \\
\hline Saltator similis & 0,01 & $0,1 \%$ & 0,01 & $0,1 \%$ & $66,7 \%$ & (2) \\
\hline Euphonia chlorotica & 0,01 & $0,0 \%$ & 0,00 & $0,0 \%$ & $0,0 \%$ & (1) \\
\hline
\end{tabular}

Ficus insipida

Pteroglossus aracari

4,96

$52,4 \%$

2,35

$98,2 \%$

$47,4 \%$

(45)

Forpus xanthopterygius

4,35

$45,9 \%$

0,00

$0,0 \%$

$0,0 \%$

Thraupis sayaca

0,16

$1,7 \%$

0,04

$1,8 \%$

$26,7 \%$

Ficus luschnathiana

\begin{tabular}{lcccccc} 
Turdus leucomelas & 7,57 & $25,8 \%$ & 7,29 & $34,7 \%$ & $96,4 \%$ & $(110)$ \\
Trichothraupis melanops & 4,11 & $14,0 \%$ & 2,52 & $12,0 \%$ & $61,5 \%$ & $(32)$ \\
Chiroxiphia caudata & 3,74 & $12,8 \%$ & 2,27 & $10,8 \%$ & $60,8 \%$ & $(34)$ \\
Hemithraupis guira & 3,06 & $10,4 \%$ & 2,04 & $9,7 \%$ & $66,7 \%$ & $(23)$ \\
Thraupis sayaca & 2,36 & $8,1 \%$ & 1,55 & $7,4 \%$ & $65,5 \%$ & $(29)$ \\
Dacnis cayana & 2,34 & $8,0 \%$ & 1,00 & $4,7 \%$ & $42,5 \%$ & $(29)$ \\
Saltator similis & 1,95 & $6,6 \%$ & 1,30 & $6,2 \%$ & $66,7 \%$ & $(26)$ \\
Tangara cayana & 1,79 & $6,1 \%$ & 1,05 & $5,0 \%$ & $59,0 \%$ & $(26)$ \\
Trogon surrucura & 0,87 & $3,0 \%$ & 0,87 & $4,1 \%$ & $100,0 \%$ & $(18)$ \\
Euphonia violacea & 0,67 & $2,3 \%$ & 0,44 & $2,1 \%$ & $66,7 \%$ & $(13)$ \\
Turdus amaurochalinus & 0,43 & $1,5 \%$ & 0,37 & $1,8 \%$ & $87,5 \%$ & $(8)$ \\
Cyanocorax chrysops & 0,36 & $1,2 \%$ & 0,27 & $1,3 \%$ & $75,0 \%$ & $(8)$ \\
Icterus cayanensis & 0,06 & $0,2 \%$ & 0,04 & $0,2 \%$ & $66,7 \%$ & $(1)$ \\
Penelope superciliaris & - & - & - & - & - & \\
\hline
\end{tabular}


Anexo 2. (Continuação)

\begin{tabular}{|c|c|c|c|c|c|c|}
\hline Espécie & $\begin{array}{c}\text { TF } \\
\text { (figos.h }^{-1} \text { ) }\end{array}$ & $\begin{array}{l}\text { \% Figos } \\
\text { removidos }\end{array}$ & $\begin{array}{c}\text { TD } \\
\text { (figos.h }^{-1} \text { ) }\end{array}$ & $\begin{array}{l}\text { \% Figos } \\
\text { dispersos }\end{array}$ & & \\
\hline \multicolumn{7}{|l|}{ Ficus obtusifolia } \\
\hline Thraupis sayaca & 15,12 & $80,6 \%$ & 6,27 & $81,8 \%$ & $41,5 \%$ & (119) \\
\hline Ramphocelus carbo & 1,34 & $7,2 \%$ & 0,62 & $8,1 \%$ & $46,0 \%$ & (29) \\
\hline Dacnis cayana & 1,29 & $6,8 \%$ & 0,45 & $5,9 \%$ & $35,1 \%$ & (19) \\
\hline Tangara cayana & 0,57 & $3,0 \%$ & 0,23 & $3,0 \%$ & $40,0 \%$ & (10) \\
\hline Turdus amaurochalinus & 0,24 & $1,3 \%$ & 0,01 & $0,2 \%$ & $5,6 \%$ & (6) \\
\hline Pitangus sulphuratus & 0,12 & $0,7 \%$ & 0,05 & $0,7 \%$ & $44,4 \%$ & (3) \\
\hline Coereba faveola & 0,04 & $0,2 \%$ & 0,01 & $0,2 \%$ & $33,3 \%$ & (1) \\
\hline Turdus leucomelas & 0,04 & $0,2 \%$ & 0,01 & $0,2 \%$ & $33,3 \%$ & (1) \\
\hline Penelope superciliaris & - & - & - & - & - & \\
\hline Saltator similis & - & - & - & - & - & \\
\hline
\end{tabular}

